\begin{tabular}{c} 
International Journal of Physical Research, 5 (2) (2017) $60-78$ \\
International Journal of Physical Research \\
SPC \\
Website: $\begin{array}{c}\text { ww.sciencepubco.com/index.php/IJPR } \\
\text { doi: } 10.14419 / \text { ijpr.v5i2.8160 } \\
\text { Research paper }\end{array}$ \\
\hline
\end{tabular}

\title{
A critical review of theoretical models for estimating global solar radiation between 2012-2016 in Nigeria
}

\author{
Nwokolo Samuel Chukwujindu *, Ogbulezie Julie C. \\ Department of Physics, Faculty of Physical Sciences, University of Calabar, Nigeria, P.O. Box 2892, Calabar, Nigeria \\ *Corresponding author E-mail: nwokolosc@stud.unical.edu.ng
}

\begin{abstract}
A routinely research of solar radiation is of vital requirement for surveys in agronomy, hydrology, ecology and sizing of the photovoltaic or thermal solar systems, solar architecture, molten salt power plant and supplying energy to natural processes like photosynthesis and estimates of their performances. However, measurement of global solar radiation is not available in most locations across in Nigeria. During the past 5 years in order to estimate global solar radiation on the horizontal surface on both daily and monthly mean daily basis, numerous empirical models have been developed for several locations in Nigeria. As a result, various input parameters have been utilized and different functional forms used. In this study aims at comparing, classifying and reviewing the empirical and soft computing models applied for estimating global solar radiation. The empirical models so far utilized were classified into eight main categories and presented based on the input parameters employed. The models were further reclassified into several main sub-classes and finally represented according to their developing year. On the whole, 145 empirical models and 42 functional forms, 8 artificial neural network models, 1 adaptive neural fuzzy inference system approach, and 1 Autoregressive Moving Average methods were recorded in literature for estimating global solar radiation in Nigeria. This review would provide solar-energy researchers in terms of identifying the input parameters and functional forms widely employed up until now as well as recognizing their importance for estimating global solar radiation using soft computing empirical models in several locations in Nigeria.
\end{abstract}

Keywords: Global Solar Radiation; Theoretical Models; Soft Computing Models; Artificial Neural Network; Autoregressive Moving Average; Adaptive Neural Fuzzy Inference System.

\section{Introduction}

From the ancient times, energy and fresh water are the two primary natural resources that engineered the basis of all human activity for refreshing and good life quality. These two resources are wholly related to each other. During the early civilizations, water power has been applied as the primary energy source. Solar energy, on the other hand, is the most ancient source, and it is the fundamental material for almost all fossil and renewable types. Simple and sophisticated instrument have been employed for harnessing solar energy since time immemorial and such applications can be traced from the early development of science and technology.

However, since the beginning of $19^{\text {th }}$ century, dwelling of fossil fuels increased tremendously toward the development of modern lifestyle across the globe. This could be attributed to ever-increasing domestic-industrial applications thereby culminating into an increase in global warming, environmental pollution, health hazards, deterioration of ecosystem and many other factors, which drive the planet towards the dark future are due to excessive exploitation of conventional fuels directly or indirectly.

In order to overcome dependency on conventional fuel, researchers and atmospheric physicists discovered that non-conventional fuels (renewable energy) which was commercially viable globally, pollutant free, easy to access and most abundant in nature can be adopted since its energy sources are vital and necessary ingredients for all human transactions and without them man's activities of all kinds will not be progress at all. Whereas, conventional energy sources are glossily limited and on the hand, the population growth, at present average rate of $2 \%$ adds extra pressure on additional energy demand. Non-conventional energy (solar energy) is among the environmentally friendly and an almost inexhaustible source for future generations. Photo synthetically active radiation (PAR) as a component of solar energy is an indispensable atmospheric parameter nature required for balance distribution of varieties of plants and perfecting the ecosystem in the horizons across different continents and regions of the world. In fact, plants need PAR as an energy requirement to convert carbon (IV) oxide $\left(\mathrm{CO}_{2}\right)$ and water $\left(\mathrm{H}_{2} \mathrm{O}\right)$ through photosynthesis into glucose, which is used to synthesize structural and metabolic energy needed for plant growth, development, respiration as well as store vegetative products that result in plant biomass as shown in equation 1 .

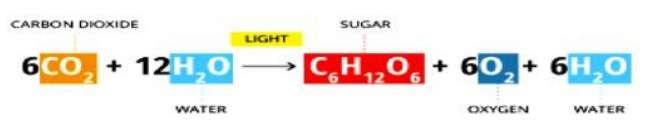

The development of affordable inexhaustible and clean solar-energy technologies will robust countries' energy security through reliance on an indigenous, inexhaustible and mostly import-independent resources, enhance sustainability, reduce pollution, lower the costs of mitigating global warming, and keep fossil-fuel prices lower than otherwise. These advantages are global. Hence, the additional costs of the incentives for early deployment should be considered learning investments; they must be wisely spent and need to be widely share [1].

The huge amount of solar-energy availability makes it a highly appealing source of electricity in spite of the effort of governments, 
scientists, researchers as well as investors so far to exploit solar energy via various technologies; solar radiation potential is fundamentally unexploited yet. The quantity of energy emitted by sun is so enormous that in case of converting only $0.1 \%$ of the solar energy reaching the earth surface to electricity with the efficiency of $10 \%$, the output power would be $17,300 \mathrm{GW}$, which is 7 times higher than the global average momentary electricity consumption in 2012 [24].

Solar energy is primarily obtained from solar radiation reaching the surface of the earth. It is an electromagnetic radiation of varying wavelengths ranging from $10^{8} \mu \mathrm{m}$ ( $\mu$ rays) to $10^{8} \mu \mathrm{m}$ (radio wave) [5]. It serves as a baseline for estimating and understanding solar radiation parameters such as diffuse solar radiation direct, solar radiation, ground reflected, reference evapotranspiration, crop evaporation and actual evaporation.

A good working knowledge of solar radiation is needed for many applications such as exciting electrons in an photovoltaic cell and supplying energy to natural processes like photosynthesis, thermal system and photovoltaic [6]; meteorology, climatology, radiation and energy budgets, water treatment processes, heating and natural lighting, agriculture and forestry [7]; air conditioning engineers and energy-conscious designers of building [8-9].

Solar radiation varies from one climate and geographical site to another. It is a function of meteorological parameters such as evaporation, effects of cloudiness, relative humidity, precipitation, temperature, sunshine duration, extraterrestrial solar radiation, and reflection of the environs; geographical parameters such as latitude longitude and elevation of the site; geometrical factors such as azimuth angle, sun azimuth angle; astronomical parameters like solar constant, earth-sun distance, solar declination and hour angle; physical parameters such as scattering air molecules, water vapour content, scattering of dust and other atmospheric constituents like $\mathrm{O}_{2}$, $\mathrm{N}_{2}, \mathrm{CO}_{2}$, and $\mathrm{O}$ [5], [10].

Global solar radiation has been measured and quantify in numerous locations in Nigeria and across the globe using a variety of measurement instrument and techniques. These assessments have involved direct measurement with meteorological measuring instrument such as Eppley pyranometer and satellite remote-sensing instrument such as Moderate-Resolutoin Imaging Spectroradiometer (MODIS) products, and meteosat-images etc.

Due to cost implication, maintenance, expertise involved in ground measurement and satellite-derived data, especially in rural and developing locations in Nigeria, numerous estimation models employing empirical, artificial neutral network and other techniques were proposed in Nigeria by solar-energy researchers that can produce global solar radiation data without the substantial cost of the instrumental network that would otherwise be needed [11-14].
Kimball [15] was the first researcher that studied on the relationship between solar radiation and sunshine duration then Angstrom [16] proposed that this relationship was linear. Prescott [17] first put the Angstrom equation in terms of extraterrestrial solar radiation. Later, for the same reason, another modification proposed by Page [18] who considered variation of the open day solar radiation with the extraterrestrial solar radiation. Since last decades, several solar-energy researchers have employed Angstrom-Prescott model globally as a baseline further developing empirical models for predicting global solar radiation using the same parameter, other meteorological parameters, geographical parameters, geometrical parameters and astronomical parameters that will best fit the local climate of their interest.

Therefore, the main purpose of this research was to carry out a critical review of theoretical models (soft computing and empirical models) fitted in literature for estimating global solar radiation at several geographical and climatic locations distributed in Nigeria as a tropical site between 2012-2016. Thus this research will determine greatly numerous utilized input variables and functional forms with their corresponding categories using empirical models and other techniques ever employed for estimating global solar radiation in Nigeria.

\section{Materials and methods}

To advance our understanding in investigating global solar radiation estimation models, the present research consisted of a critical literature review with a specific focus on research related to empirical and soft computing models employed for estimating global solar radiation. A critical review differs from a traditional general review as it adopts a replicable, scientific and transparent process. The scene of a critical review of literature is to present a fair evaluation of a research topic by a rigorous and systematic method; help in identifying any research gaps in the current research in order to suggest further advancements; and to summaries and provide background for new research activities. This leads to developing collective insights based on theoretical synthesis of previous studies. The design of the critical review recorded in this research started in November 2016. After several refinements and advancements, publication's search was started in December 2016. The Fig. 1 presents the research method employed for the critical review. 


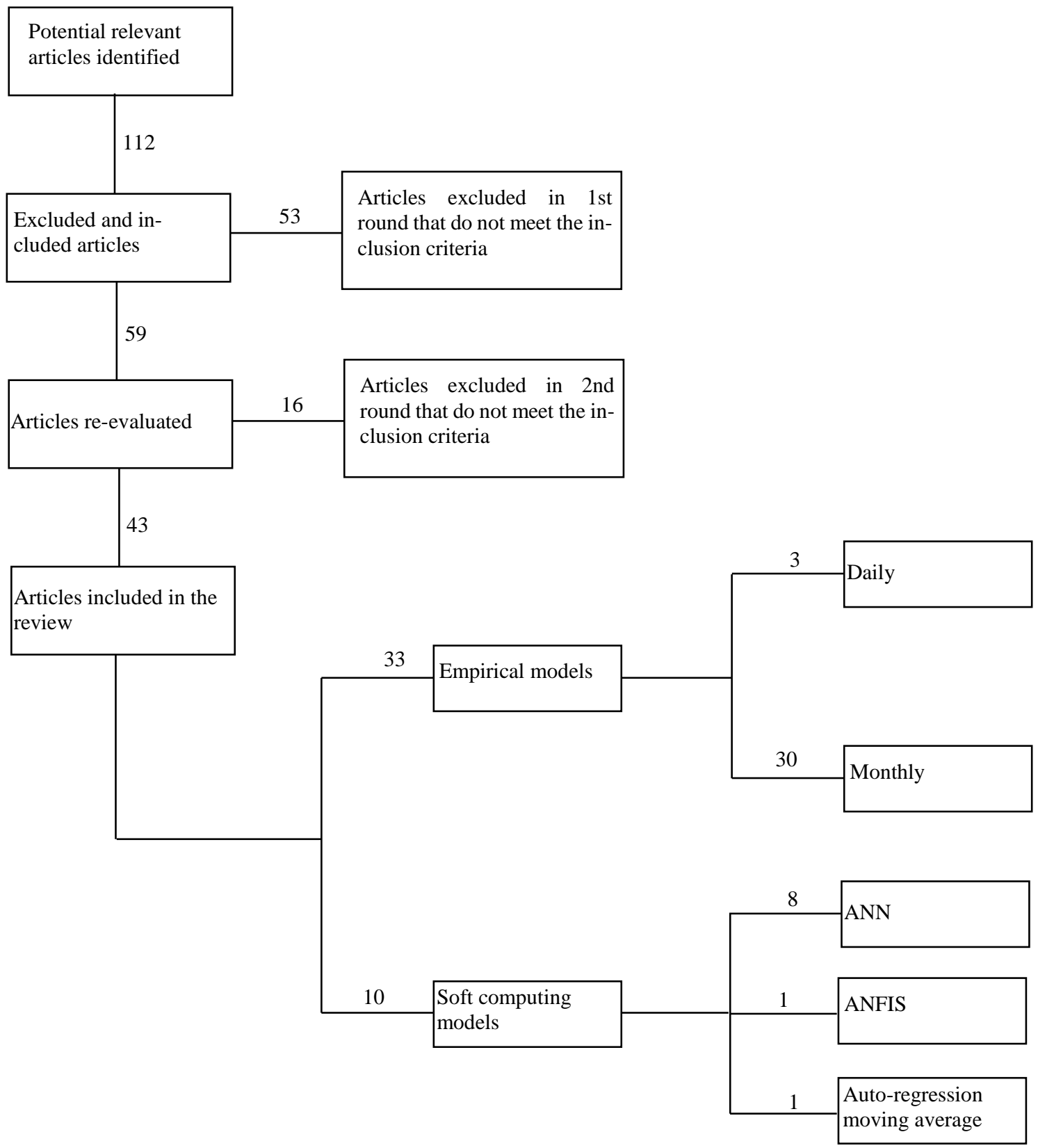

Fig. 1: Criteria Review Flow Diagram.

\subsection{Evaluation technique}

This research is planned by purposing research questions relevant to the objectives. The following steps present the data sources, search strategies, the publication selection and screening criteria.

\subsubsection{Review objectives and research questions}

With the increased application of soft computing methods in estimating global solar radiation over empirical techniques, it has become important to study and compare the relevant of soft computing techniques over empirical models for global solar radiation. Therefore, the main focus of this research was to compare the accuracy of employing soft computing techniques over conventional empirical models in Nigeria.

This research advocates the way how soft computing techniques are more important than conventional empirical models to perform global solar radiation estimations. Since research questions guide the design of the review process, specifying them is the most essential part of any critical review. To actualize these objectives, the research questions are formulated as follows:

1) Which techniques of global solar radiation estimation are dispersed across many publications, the work will be employed as a way to structure the analysis of the body of knowledge on a single work sheet on global solar radiation estimation. This will enable the researcher to determine which techniques get the most or the least attractive results and can be most adventitious.

2) How effective is the soft computing approach over empirical modeling in the field? The aim of this second research question is to ascertain the current maturity of predictive soft computing modeling over empirical method for estimation of global solar radiation. In this research, accounting on the wide application of research on global solar radiation employing empirical models, many different methods can be envisaged to contribute better estimation. The present review will help researcher and solar-energy installers to define global solar radiation data with greater precision in situation where meteorological stations with World Meteorological Organization recommended measuring instrument for global solar radiation, and other meteorological parameters are lacking as it is in the case of Nigeria where Nigerian Meteorological Agency still employed Gunn-Bellani distillate solar radiation integrator instead of thermopile pyranometer or rotating shadowband irradiometer to measure solar radiation in several locations distributed across the nation. 


\subsubsection{Search strategy}

After specifying the research objectives and questions, the research started with the formulation of a formal search strategy to analyze all available empirical materials corresponding to the objective of the review. The plan involved defining the search space, which included electronic databases as presented in Table 1. This research performed journal search to find publications relevant to the scope of the study. The automatic search was performed on the following publishers' databases: ScienceDirect, SpringerLink, Wiley, Google Scholar, Research gates, and Academia as presented in Table 1.

Table 1: Search Sources

$\begin{array}{ll}\text { Electronic databases } & \text { ScienceDirect } \\ \text { SpringerLink } \\ \text { Wiley } \\ \text { Google Scholar } \\ \text { Researchgates } \\ \text { Academia }\end{array}$

Search Item Journals, workshop and conference papers

Search applied on

Full text to find papers within the scope and not omit any paper that did not include the research keywords in the title or abstract

English

Language

From January 2012 to December 2016

Publication period

\subsubsection{Search criteria}

The potential search criteria employed for this review is defined as follows. The first step begins by setting certain practical screening criteria to ensure that only quality publications are included in the paper. During the first search, therefore, conference articles, workshop papers and book review articles were excluded, targeting instead for a focus on journal publications. This delimitation also secured the focus on quality publications related to global solar radiation estimation and related concepts. No other quality criteria were used (e.g. journal rankings) for selection. The selection process also excluded articles that were not peer-reviewed or not written in English Language. The selection string is developed by specifying the main terms of the phenomena under the research scope. Numerous pilot searches were performed to refine the keywords in the search string employing trial and error. The terms whose inclusion did not yield additional publications in the automatic searches are removed. After numerous iterations, following search string is settled presented in Table 2 .

Table 2: Keywords Operationalized for Search

\begin{tabular}{|c|c|c|}
\hline \multicolumn{2}{|l|}{ Search Clouds } & \multirow{2}{*}{$\begin{array}{l}\text { Exemplary Search } \\
\text { String }\end{array}$} \\
\hline $\begin{array}{l}\text { Soft Computing } \\
\text { Techniques }\end{array}$ & Empirical Models & \\
\hline $\begin{array}{l}\text { Soft computing } \\
\text { models, artificial } \\
\text { neural networks } \\
\text { (ANN), estimation } \\
\text { models, artificial } \\
\text { neuro-fuzzy infer- } \\
\text { ence system (AN- } \\
\text { FIS), autoregression } \\
\text { moving average, } \\
\text { support vector ma- } \\
\text { chine, genetic pro- } \\
\text { gramming and sat- } \\
\text { ellite-based method, } \\
\text { estimation models } \\
\text { on hourly, daily and }\end{array}$ & $\begin{array}{l}\text { Sunshine-based } \\
\text { models, cloud } \\
\text { cover-based mod- } \\
\text { els, temperature- } \\
\text { based models, ex- } \\
\text { traterrestrial-based } \\
\text { models, monthly- } \\
\text { based models, soil } \\
\text { temperature-based } \\
\text { models, and hybrid } \\
\text { parameter-based } \\
\text { models for estimat- } \\
\text { ing global solar ra- } \\
\text { diation on hourly, }\end{array}$ & $\begin{array}{l}\text { Global solar radia- } \\
\text { tion estimations us- } \\
\text { ing soft computing } \\
\text { such as artificial } \\
\text { neuro-fuzzy infer- } \\
\text { ence system (AN- } \\
\text { FIS), autoregression } \\
\text { moving average, } \\
\text { support vector ma- } \\
\text { chine, genetic pro- } \\
\text { gramming and sat- } \\
\text { ellite-based method } \\
\text { on hourly, daily and } \\
\text { monthly basis in }\end{array}$ \\
\hline
\end{tabular}

$\begin{array}{lll}\begin{array}{ll}\text { monthly basis in } \\ \text { Nigeria }\end{array} & \begin{array}{l}\text { daily and monthly } \\ \text { basis in Nigeria }\end{array} & \begin{array}{l}\text { Nigeria. Global so- } \\ \text { lar radiation estima- } \\ \text { tions employing } \\ \text { empirical models }\end{array} \\ & \text { such as Sunshine- } \\ \text { based models, } \\ \text { cloud cover-based } \\ \text { models, tempera- } \\ \text { ture-based models, } \\ \text { extraterrestrial- } \\ \text { based models, } \\ \text { monthly-based } \\ \text { models, soil tem- } \\ \text { perature-based } \\ \text { models, and hybrid } \\ \text { parameter-based } \\ \text { models for estimat- } \\ \text { ing global solar ra- } \\ \text { diation on hourly, } \\ \text { daily and monthly } \\ \text { basis in Nigeria }\end{array}$

\subsubsection{Inclusion and exclusion criteria}

The purpose of the present review is to compare the performance of soft computing and empirical models for estimating global solar radiation. Only publication that discussed hourly, daily or monthly estimation models were included. However, the inclusion criteria for publication selected for full analysis were as follows:

Inclusion Criteria: Studies that discussed daily or monthly global solar radiation models employing soft computing or empirical models were retained

Exclusion Criteria: Studies that do not focus explicitly on either soft computing techniques, empirical models, or both techniques for estimating global solar radiation. Studies that do not meet inclusion criteria and scope of the study.

Based on the criteria investigation, each paper was either included or excluded. In case where the researcher views on the abstract screening differed, the researchers scanned the entire paper for relevance. This time-consuming process culminated in including 43 papers out of 59 that were included after the inclusion criteria. The original search retrieved 112 studies as shown in Table 3. Hence, this critical review is based on 43 articles with a specific focus on global solar radiation estimation employing either soft computing or empirical models or both models for estimating global solar radiation in Nigeria.

Table 3

Search Result and Fitted Articles according to Search Terminology

\begin{tabular}{|llllll|}
\hline Databases & Retrieved & Round 1 & & Round 2 \\
\cline { 3 - 6 } & & Included & Excluded & Included & Excluded \\
\hline ScienceDirect & 28 & 4 & 24 & 4 & 0 \\
SpringerLink & 4 & 3 & 1 & 3 & 0 \\
Wiley & 8 & 2 & 6 & 2 & 0 \\
Google & 59 & 47 & 12 & 31 & 16 \\
Researchgates & 11 & 2 & 9 & 2 & 0 \\
Academia & 2 & 1 & 1 & 1 & 0 \\
Total & 112 & 59 & 53 & 43 & 16 \\
\hline
\end{tabular}

\subsection{Fundamental parameters}

The fundamental parameter of sunshine duration fraction, daily extraterrestrial radiation on the horizontal surface is significant for the estimation of global solar radiation. Sunshine duration fraction is the ratio of actual sunshine duration to maximum possible sunshine duration expressed mathematically as:

$S_{o}=\frac{2}{15} \cos ^{-1}(-\tan \varphi \tan \delta)$

$\delta=23.45 \sin \left[\frac{360(n+284)}{365}\right]$ 
Where $\varphi$ is the latitude, $\delta$ is the solar declination given by Yaniktepe and Genc [6] and $n$ the number of days of the year starting from first January. The daily extraterrestrial solar radiation is the solar radiation intercepted by horizontal surface during a day without the atmosphere expressed theoretically as given by Yaniktepe and Genc [6]:

$$
H_{o}=\frac{24}{\pi} I_{S C}\left(\begin{array}{l}
1 \\
+0.033 \cos \frac{360 n}{365}
\end{array}\right) \times\left(\begin{array}{l}
\cos \varphi \cos \delta \sin \omega_{S} \\
2 \pi \omega_{S} \\
+\frac{360}{360} \sin \varphi \sin \delta
\end{array}\right)
$$

Where the mean sunrise hour angle $\left(\omega_{s}\right)$ can be evaluated as:

$$
\omega_{s}=\cos ^{-1}[\tan \delta \tan \varphi]
$$

ISC is the solar constant and other symbols retain their usual meaning

\section{Empirical models}

An empirical model relates global solar radiation with other easily measureable variables such as sunshine duration, temperature, relative humidity, dew point temperature, precipitation and cloud cover by employing concise mathematical functions. As a result of its simplicity and high operability, the empirical model is much more convenient for engineering applications.

Several empirical models have been reported in literature for estimating global solar radiation on the horizontal surface $(\mathrm{H})$ either on daily mean basis (DB) or monthly mean daily basis (MB) in Nigeria. In this review, the global solar radiation models are classified according to the basis of their input parameters applied in correlating with the clearness index. The clearness index $\left(\mathrm{k}_{\mathrm{t}}\right)$ indicates the percentage depletion by the sky of the incoming solar radiation and therefore, gives both the level of availability of solar radiation and changes in the atmospheric condition in a given environment [1112]. Mathematically, clearness index is the ratio of horizontal global solar radiation (often measured and collected from Nigeria Meteorological Station (NIMET), International Institute of Tropica Agriculture (IITA), National Aeronautics and Space Administration (NASA) atmospheric science data center by researchers in $\mathrm{Ni}$ geria) to the extraterrestrial solar radiation $\left(\mathrm{H}_{\mathrm{o}}\right)$ on a daily or monthly basis as found in literature expressed as:

$$
k_{t}=\frac{H}{H_{o}}
$$

It has been accepted that global solar radiation is relatively affected by meteorological parameters, astronomical factors, geographical factors, and geometrical factors [5, 10]. This could be attributed to the uniqueness of local climate in determining the meteorological and atmospheric parameters that best fit that particular locality. This also depends on the availability of input meteorological/atmospheric parameter(s) that a given radiometric station or an individual is capable of measuring routinely, which finally turned out to be the best input parameter at the disposal of the researcher for predicting global solar radiation in that location. Thus, in Nigeria, the models for estimating global solar radiation can be classified into eight (8) following categories based on the employed meteorological and atmospheric parameters via:

1) Sunshine-based models

2) Cloud-based models

3) Temperature-based models

4) Relative Humidity-based models

5) Precipitation-based models

6) Extraterrestrial Solar Radiation-based models

7) Monthly-based models

8) Hybrid Parameter-based models

\subsection{Sunshine-based models}

Sunshine-based models are the most frequently applied model for estimating global solar radiation in Nigeria owing to the fact that after investigating a large number of studies, the authors have found that sunshine duration fraction has the highest influence on the accuracy, followed by ambient temperature besides its availability and reliable measured sunshine duration data in most meteorological stations in Nigeria. This radiometric model pioneered by Angstrom [16] and modified by Prescott [17] and other researchers have been applied by a countless number of solar radiation researchers for estimating the monthly mean daily global solar radiation on the horizontal surface for several stations within Nigeria and across the globe by determining the empirical constants $(\mathrm{a}, \mathrm{b})$ of equation (7) employing meteorological parameters of the site of interest as stated in this class. Apart from an Angstrom-Prescott type model, those fitted by Rietveld [19] seems to be universally applicable. However, Ohunakin et al. [20] and Adaramola [21] employed empirical model for estimating monthly mean daily global solar radiation on the horizontal surface with a fraction of sunshine duration for several locations in Nigeria; the result showed better performance and high accuracy in the fitted sites as compared to reported models in literature that seems to be universally applicable. Countless empirical models based on the Angstrom-Prescott model and other modified (exponential form, logarithm form, second order, third order and power form) models applied for estimating DB and MB global solar radiation in literature are introduced according to their developing year. Thus, the relation is given as:

$$
\frac{H}{H_{o}}=a+b\left(\frac{S}{S_{o}}\right)
$$

Where $\mathrm{a}$ and $\mathrm{b}$ are the empirical constants, $\mathrm{S}$ is the measure of sunshine duration and $\mathrm{S}_{\mathrm{o}}$ is the daily maximum possible sunshine duration.

\subsubsection{Group 1}

Empirical models from this group are parameterize as the first-order polynomial function of the relative sunshine duration proposed by Angstrom[16] and Prescott[17] and other modified (power form, exponential form, logarithm form, second order, third order) models according to their functional forms and developing year are introduced.

Ituen et al. [22] proposed the following MB model for Uyo as:

$$
\frac{H}{H_{o}}=0.239+0.585\left(\frac{S}{S_{o}}\right)
$$

Adaramola [21] established the following MB model for Akure as:

$$
\frac{H}{H_{o}}=0.249+0.566\left(\frac{S}{S_{o}}\right)
$$

Yakubu and Medugu [23] developed the following MB model for Abuja as:

$$
\frac{H}{H_{o}}=0.30+0.53\left(\frac{S}{S_{o}}\right)
$$

Musa et al. [24] calibrated the following MB model for Maiduguri as:

$$
\frac{H}{H_{o}}=0.287742+0.547354\left(\frac{S}{S_{o}}\right)
$$

Isikwue et al. [25] established the following MB model for Makurdi as: 


$$
\frac{H}{H_{o}}=0.138+0.488\left(\frac{S}{S_{o}}\right)
$$

Kolebaje and Mustapha [26] reported the following MB model for Lokoja.

$$
\frac{H}{H_{o}}=0.258+0.612\left(\frac{S}{S_{o}}\right)
$$

Ohunakin et al. [20] established the following MB model for Osogbo as:

$$
\frac{H}{H_{o}}=0.1943+0.3986\left(\frac{S}{S_{o}}\right)
$$

Solomon [27] developed MB model for Nsukka as:

$$
\frac{H}{H_{o}}=0.1150+0.5666\left(\frac{S}{S_{o}}\right)
$$

Gana and Akpootu [28] calibrated the following MB model for Kebbi as:

$$
\frac{H}{H_{o}}=0.351+0.420\left(\frac{S}{S_{o}}\right)
$$

Gana and Akpootu [29] fitted the following MB model for Bauchi as:

For Bauchi

$$
\frac{H}{H_{o}}=0.389+0.358\left(\frac{S}{S_{o}}\right)
$$

Isikwue et al. [30] established the following MB model for Makurdi as:

$$
\frac{H}{H_{o}}=0.461+0.605\left(\frac{S}{S_{o}}\right)
$$

Okonkwo and Nwokoye [31] derived the following MB model for Minna as:

$$
\frac{H}{H_{o}}=0.244+0.415\left(\frac{S}{S_{o}}\right)
$$

Ogolo [32] suggested the following MB model for Nigeria as:

$$
\frac{H}{H_{o}}=0.281+0.414\left(\frac{S}{S_{o}}\right)
$$

Nwokoye and Okonkwo [33] reported the following MB model for Bida as:

$$
\frac{H}{H_{o}}=0.11+0.79\left(\frac{S}{S_{o}}\right)
$$

Kaltiya et al. [34] obtained the following MB model for February July In Makurdi as:

$$
\frac{H}{H_{o}}=0.24+0.57\left(\frac{S}{S_{o}}\right)
$$

Sheriff et al. [35] registered the following MB model for Maiduguri as:
$\frac{H}{H_{o}}=0.288+0.547\left(\frac{S}{S_{o}}\right)$

Ike [36] derived the following MB model for Akure as:

$$
\frac{H}{H_{o}}=0.191504+0.44218\left(\frac{S}{S_{o}}\right)
$$

Gana et al. [37] calibrated the following MB model for Sokoto

$$
\frac{H}{H_{o}}=0.34+0.43\left(\frac{S}{S_{o}}\right)
$$

Ayodele and Ogunjuyigbe [38] developed the following DB model for Ibadan:

$$
\frac{H}{H_{o}}=0.32+0.14\left(\frac{S}{S_{o}}\right)
$$

Sani et al. [39] developed the following MB model for Kano as:

$$
\frac{H}{H_{o}}=0.045+0.051\left(\frac{S}{S_{o}}\right)
$$

Adesina et al. [40] established the following MB model for Nasarawa as:

$$
\frac{H}{H_{o}}=0.01+0.75\left(\frac{S}{S_{o}}\right)
$$

Olatona and Adeleke [41] fitted the following MB model for Ibadan

$\frac{H}{H_{o}}=0.24+0.31\left(\frac{S}{S_{o}}\right)$

Innocent et al. [42] proposed the following MB model for Gusua from $1995-2000$ as:

$$
\frac{H}{H_{o}}=0.2950+0.5317\left(\frac{S}{S_{o}}\right)
$$

Azoom et al. [43] fitted the following MB model for selected locations in Port Harcourt as:

$$
\frac{H}{H_{o}}=0.202+0.775\left(\frac{S}{S_{o}}\right)
$$

Akpan and Osu [44] developed the following MB model for Port Harcourt as:

$$
\frac{H}{H_{o}}=0.155+0.545\left(\frac{S}{S_{o}}\right)
$$

Ogunsanwo et al. [45] developed the following MB model for Ijebu-Odo as:

$$
\frac{H}{H_{o}}=0.321+0.206\left(\frac{S}{S_{o}}\right)
$$

Boluwaji and Onyedi [46] calibrated the following MB model for Kano.

$\frac{H}{H_{o}}=0.314+0.491\left(\frac{S}{S_{o}}\right)$ 
Okundamiya et al. [47] obtained the following MB model for Benin City

$$
\frac{H}{H_{o}}=0.2361+0.6213\left(\frac{S}{S_{o}}\right)
$$

\subsubsection{Group 2}

The empirical models from this group employed second order Angstrom-Prescott type model for estimating global solar radiation in different locations. The empirical model has the form:

$$
\frac{H}{H_{o}}=a+b\left(\frac{S}{S_{o}}\right)+c\left(\frac{S}{S_{o}}\right)^{2}
$$

Where $\mathrm{a}, \mathrm{b}, \mathrm{c}$ are the empirical constants and other symbols retain their usual meaning.

Kolebaje and Mustapha [26] developed the following MB model for Lokoja as:

$$
\frac{H}{H_{o}}=0.320+b\left(0.357 \frac{S}{S_{o}}\right)+-0.252\left(\frac{S}{S_{o}}\right)^{2}
$$

Gana and Akpootu [28] fitted the following MB model for Kebbi as:

$$
\frac{H}{H_{o}}=0.1195+1.232\left(\frac{S}{S_{o}}\right)-0.694\left(\frac{S}{S_{o}}\right)^{2}
$$

Ohunakin et al. [20] developed the following MB model for Osogbe as:

$$
\frac{H}{H_{o}}=0.0836+1.0054\left(\frac{S}{S_{o}}\right)-0.7646\left(\frac{S}{S_{o}}\right)^{2}
$$

Gana et al. [37] obtained the following MB model for Sokoto as:

$$
\frac{H}{H_{o}}=0.119+1.234\left(\frac{S}{S_{o}}\right)-0.695\left(\frac{S}{S_{o}}\right)^{2}
$$

Nwokoye and Okonkwo [33] registered the following MB mode for Bida as:

$$
\frac{H}{H_{o}}=0.025+1.125\left(\frac{S}{S_{o}}\right)-0.308\left(\frac{S}{S_{o}}\right)^{2}
$$

Okonkwo and Nwokoye [48] developed the following MB model for Minna as:

$$
\frac{H}{H_{o}}=0.231+0.463\left(\frac{S}{S_{o}}\right)-0.044\left(\frac{S}{S_{o}}\right)^{2}
$$

Sani et al. [39] established the following MB model for Kano as:

$$
\frac{H}{H_{o}}=0 . .010+0.058\left(\frac{S}{S_{o}}\right)-0.001\left(\frac{S}{S_{o}}\right)^{2}
$$

Ayodele and Ogunjuyigbe [49] proposed the following DB model for Ibadan.

$$
\frac{H}{H_{o}}=0.38-0.20\left(\frac{S}{S_{o}}\right)+0.35\left(\frac{S}{S_{o}}\right)^{2}
$$

\subsubsection{Group 3}

The empirical models from this group employed third order Angstrom-Prescott type model for estimating global solar radiation for different locations. The empirical model is in the form:

$$
\frac{H}{H_{o}}=a+b\left(\frac{S}{S_{o}}\right)+c\left(\frac{S}{S_{o}}\right)^{2}+d\left(\frac{S}{S_{o}}\right)^{3}
$$

Where a, b, c and d are the empirical constants and other symbols retain their usual meaning.

Gana et al. [37] calibrated the following MB model for Sokoto as:

$$
\frac{H}{H_{o}}=0.114+1.254\left(\frac{S}{S_{o}}\right)-0.725\left(\frac{S}{S_{o}}\right)^{2}+0.015\left(\frac{S}{S_{o}}\right)^{3}
$$

Nwokoye and Okonkwo [33] proposed the following MB model for Bida as:

$$
\frac{H}{H_{o}}=0.050+0.971\left(\frac{S}{S_{o}}\right)-0.200\left(\frac{S}{S_{o}}\right)^{2}+0.001\left(\frac{S}{S_{o}}\right)^{3}
$$

Sani et al. [39] established the following MB model for Kano as:

$$
\frac{H}{H_{o}}=1.561-0.365\left(\frac{S}{S_{o}}\right)+0.037\left(\frac{S}{S_{o}}\right)^{2}-0.001\left(\frac{S}{S_{o}}\right)^{3}
$$

Ayodele and Ogunjuyigbe [49] obtained the following DB model for Ibadan.

$$
\frac{H}{H_{o}}=0.38-0.14\left(\frac{S}{S_{o}}\right)+0.18\left(\frac{S}{S_{o}}\right)^{2}+0.12\left(\frac{S}{S_{o}}\right)^{3}
$$

\subsubsection{Group 4}

In this group, clearness index is correlated to non-linear sunshine duration $(\mathrm{S})$ relation as a modification from Angstrom-Prescott type model in the form:

$\frac{H}{H_{o}}=a\left(\frac{1}{S}\right)$

Okundamiya et al. [47] estimated the following MB model for Benin City.

$\frac{H}{H_{o}}=0.7649\left(\frac{1}{S}\right)$

\subsubsection{Group 5}

In this group, clearness index is related with the rational form of relative sunshine duration (S) as a modification from AngstromPrescott type model in the form

$\frac{H}{H_{o}}=a\left(\frac{1}{S / S_{o}}\right)$

Gana and Akpootu [28] developed the following MB model for Kebbi as:

$$
\frac{H}{H_{o}}=0.747\left(\frac{1}{S / S_{o}}\right)
$$

\subsubsection{Group 6}

In this sub-class, Angstrom-Prescott type model was modified by correlating clearness index with power form of relative sunshine duration as: 


$$
\frac{H}{H_{o}}=a\left(\frac{S}{S_{o}}\right)^{b}
$$

Gana and Akpootu [28] established the following MB model for Kebbi as:

$\frac{H}{H_{o}}=0.392\left(\frac{S}{S_{o}}\right)^{0.714}$

Nwokoye and Okonkwo [33] obtained the following MB model for Bida as:

$$
\frac{H}{H_{o}}=0.880\left(\frac{S}{S_{o}}\right)^{0.79}
$$

\subsubsection{Group 7}

In this sub-class, Angstrom-Prescott type model was modified by correlating clearness index with exponential form of relative sunshine duration as:

$$
\frac{H}{H_{o}}=a e^{b\left(S / S_{o}\right)}
$$

Ayodele and Ogunjuyigbe [49] calibrated the following DB model for Ibadan.

$$
\frac{H}{H_{o}}=0.24 e^{0.09\left(S / S_{o}\right)}
$$

\subsubsection{Group 8}

Angstrom-Prescott type model was modified in this group by correlating clearness index with logarithm form of relative sunshine duration as:

$$
\frac{H}{H_{o}}=a+b \log \left(\frac{S}{S_{o}}\right)
$$

Ayodele and Ogunjuyigbe [49] proposed the following DB model for Ibadan.

$$
\frac{H}{H_{o}}=0.42+0.088 \log \left(\frac{S}{S_{o}}\right)
$$

\subsection{Cloud cover based models}

The presence of cloud cover affects the amount of global solar radiation in a particular location as result of its scattered effects on it. The higher the cloud covers, the lower the global solar radiation that will be obtained in given location. Cloud cover is the fraction of the sky obscured by clouds in a location measurable by ground instrument or satellite-derived observation. The assumption that cloud cover is an indication of the global solar power of the atmosphere is the basis for cloud cover based models in this section. The meteorological variable is often employed for estimating global solar radiation in Nigeria because of its availability in weather stations across the nation.

\subsubsection{Group 1}

In this group, the clearness index is correlated with cloud cover (C) in the form:

$$
\frac{H}{H_{o}}=a+b(C)
$$

Okundamiya et al. [47] proposed the following MB models for Benin City.
$\frac{H}{H_{o}}=0.7374-0.0528(C)$

\subsection{Temperature-based models}

Temperature-based model is an adaptation of sunshine-based model pioneered by Angstrom-Prescott type model. As a result of the availability of the meteorological variable in most weather stations, solar energy researchers often use this radiometric parameter for estimating global solar radiation in Nigeria. It has been observed that cloudiness, relative humidity, elevation, topography, latitude, proximity to a large body of water other than solar radiation influences the temperature difference in a particular geographical location. This is the basis for employing temperature parameter as an input variable for estimating global solar radiation by solar energy researchers. In this class, clearness index is a function of mean temperature $\left(\mathrm{T}_{\text {mean }}\right)$, maximum temperature $\left(\mathrm{T}_{\max }\right)$, minimum temperature $\left(\mathrm{T}_{\min }\right)$ and temperature ratio $\left(\mathrm{T}_{\mathrm{R}}\right)$.

\subsubsection{Group 1}

In this group, clearness index is correlated with maximum temperature in the form.

$\frac{H}{H_{o}}=a+b\left(T_{\max }\right)$

Ituen et al. [22] established the following MB model for Uyo

$\frac{H}{H_{o}}=-0.229+0.02\left(T_{\max }\right)$

Okonkwo and Nwokoye [31] proposed the following MB model for Minna as:

$\frac{H}{H_{o}}=0.093+0.011\left(T_{\max }\right)$

\subsubsection{Group 2}

In this class, clearness index is correlated with temperature ratio in the following form.

$$
\frac{H}{H_{o}}=a+b\left(T_{R}\right)
$$

Adaramola [21] estimated the following MB model for Akure as:

$$
\frac{H}{H_{o}}=1.4192-1.1973\left(T_{R}\right)
$$

Okonkwo and Nwokoye [31] developed the following MB model for Minna as:

$$
\frac{H}{H_{o}}=0.955-0.709\left(T_{R}\right)
$$

Muhammad and Darma [50] fitted the following MB model for Kano as:

$$
\frac{H}{H_{o}}=1.2577-1.0167\left(T_{R}\right)
$$

Kolebaje et al. [51] reported the following MB model for Ikeja as:

$$
\frac{H}{H_{o}}=2.024-2.136\left(T_{R}\right)
$$




\subsubsection{Group 3}

In this group, clearness index is correlated with the difference between maximum and minimum temperature $(\Delta \mathrm{T})$ employing Hargreaves and Allen [52] model in the form:

$\frac{H}{H_{o}}=a(\Delta T)^{0.5}$

Adaramola [21] estimated the following MB model for Akure as:

$\frac{H}{H_{o}}=0.1945(\Delta T)^{0.5}$

Ohunakin et al. [20] developed the following MB model for Osogbo as:

$\frac{H}{H_{o}}=0.1141(\Delta T)^{0.5}$

\subsubsection{Group 4}

In this sub-class, clearness index is correlated with the difference between maximum and minimum temperature $(\Delta \mathrm{T})$ employing Hargreaves and Samani [53] model as:

$$
\frac{H}{H_{o}}=a+b(\Delta T)^{0.5}
$$

Kolebaje and Mustapha [26] estimated the following MB model for Lokoja as:

$$
\frac{H}{H_{o}}=0.229+0.106(\Delta T)^{0.5}
$$

Ohunakin et al. [20] developed the following MB model for Osogbo as:

$$
\frac{H}{H_{o}}=0.1020+0.0818(\Delta T)^{0.5}
$$

Kolebaje and Mustapha [26] estimated the following MB model for Ikeja.

$$
\frac{H}{H_{o}}=-0.318+0.271(\Delta T)^{0.5}
$$

Ayodele and Ogunjuyigbe [38] developed the following MB models for Ibadan as:

$$
\frac{H}{H_{o}}=0.16+0.068(\Delta T)^{0.5}
$$

\subsubsection{Group 5}

In this group, clearness index is correlated with difference between maximum and minimum temperature $(\Delta \mathrm{T})$ using Garcia [54] model in the form:

$$
\frac{H}{H_{o}}=a+b\left(\frac{\Delta T}{S_{o}}\right)
$$

Kolebaje and Mustapha [26] fitted the following MB model for Lokoja as:

$$
\frac{H}{H_{o}}=0.422+0.169\left(\frac{\Delta T}{S_{o}}\right)
$$

Ayodele and Ogunjuyigbe [38] developed the following MB model for Ibadan as:

$$
\frac{H}{H_{o}}=0.28+0.111\left(\frac{\Delta T}{S_{o}}\right)
$$

Boluwaji and Oyedum [46] calibrated the following MB model for Kano as:

$$
\frac{H}{H_{o}}=0.430+0.176\left(\frac{\Delta T}{S_{o}}\right)
$$

Kolebaje et al. [51] proposed the following MB model for Ikeja as:

$$
\frac{H}{H_{o}}=0.094+0.523\left(\frac{\Delta T}{S_{o}}\right)
$$

\subsubsection{Group 6}

In this group, clearness index is correlated with second order of difference between maximum and minimum temperature $(\Delta T)$ using Garcia [54] model in the form:

$$
\frac{H}{H_{o}}=a+b\left(\frac{\Delta T}{S_{o}}\right)+c\left(\frac{\Delta T}{S_{o}}\right)^{2}
$$

Ayodele and Ogunjuyigbe [49] developed the following MB model for Ibadan as:

$\frac{H}{H_{o}}=0.052+0.67\left(\frac{\Delta T}{S_{o}}\right)-0.27\left(\frac{\Delta T}{S_{o}}\right)^{2}$

\subsubsection{Group 7}

In this sub-class, clearness index is correlated with third order of difference between maximum and minimum temperature $(\Delta \mathrm{T})$ using Garcia [54] model as:

$\frac{H}{H_{o}}=a+b\left(\frac{\Delta T}{S_{o}}\right)+c\left(\frac{\Delta T}{S_{o}}\right)^{2}+d\left(\frac{\Delta T}{S_{o}}\right)^{3}$

Ayodele and Ogunjuyigbe [49] fitted the following MB model for Ibadan.

$$
\frac{H}{H_{o}}=-0.086+1.20\left(\frac{\Delta T}{S_{o}}\right)-0.95\left(\frac{\Delta T}{S_{o}}\right)^{2}+0.25\left(\frac{\Delta T}{S_{o}}\right)^{3}
$$

\subsubsection{Group 8}

In this group, clearness index is correlated with the exponential form of Garcia [54] model in the form:

$\frac{H}{H_{o}}=a+e^{b\left(\Delta T / S_{o}\right)}$

Ayodele and Ogunjuyigbe [49] developed the following MB model for Ibadan.

$\frac{H}{H_{o}}=0.24+e^{0.064\left(\Delta T / S_{o}\right)}$

\subsubsection{Group 9}

In this group, clearness index is correlated with the logarithm form of Garcia [54] model in the form: 


$$
\frac{H}{H_{o}}=a+b \log \left(\frac{\Delta T}{S_{o}}\right)
$$

Ayodele and Ogunjuyigbe [49] developed the following MB model for Ibadan.

$$
\frac{H}{H_{o}}=0.45+0.39 \log \left(\frac{\Delta T}{S_{o}}\right)
$$

\subsection{Relative humidity-based models}

Relative humidity-based models are modification of the sunshine hour model proposed by Angstrom-Prescott [16], [17] for estimating global solar radiation. This could be attributed to the availability of the meteorological parameter in most weather stations in both developing and developed countries across the globe especially where sunshine and temperature models are not available or where sunshine and temperature could not fit the observed data accurately Solar energy researchers applied the principle of changes in relative humidity, which is influenced by the degree of the cloud cover, temperature difference, and solar radiation and formulated several temperature-based models that are empirical in nature taking numerous forms as shown in this section.

\subsubsection{Group 1}

In this group, clearness index is related with relative humidity $(\mathrm{RH})$ in the forms:

$$
\frac{H}{H_{o}}=a+b\left(\frac{R H}{100}\right)
$$

Or

$$
\frac{H}{H_{o}}=a+b(R H)
$$

Ituen et al. [22] correlated the following MB model for Uyo as:

$$
\frac{H}{H_{o}}=-0.589-0.280\left(\frac{R H}{100}\right)
$$

Adaramola [21] related the following MB model for Akure as:

$$
\frac{H}{H_{o}}=0.8453-0.4603\left(\frac{R H}{100}\right)
$$

Muhammed and Darma [50] developed the following MB mode for Kano as:

$$
\frac{H}{H_{o}}=0.8907-0.0055(R H)
$$

Kolebaje et al. [51] reported the following MB model for Ikeja as:

$$
\frac{H}{H_{o}}=2.024-0.019(R H)
$$

\subsection{Precipitation-based models}

In this section, solar energy researchers applied precipitation-based models as an adoption or modification of Angstrom-Prescott type model for estimating global solar radiation on the horizontal surface owing to its availability and influence especially where sunshine duration, temperature, relative humidity and cloud cover parameters are not available in the tropics (Nigeria).

\subsubsection{Group 1}

In this group, clearness index is correlated with precipitation in the form:

$$
\frac{H}{H_{o}}=a+b(P)
$$

Adaramola [21] developed the following MB model for Akure as:

$$
\frac{H}{H_{o}}=0.5904-0.0218(P)
$$

\subsection{Monthly-based models}

Monthly-based model are used for estimating global solar radiation as a result its variation effect on global solar radiation striking at ground level in a particular location due to the movement on the earth on its axis. Thus, the functional form and model applied in Nigeria are introduced in this section.

\subsubsection{Group 1}

In this group, clearness index is corrected to month of the year (M) in the form:

$H=a+b(M)+c(M)^{2}+d(M)^{3}$

Ugwuoke and Okeke [55] developed the following MB model for Nsukka as:

$H=409.5505+19.4222(M)-9.464(M)^{2}+0.6369(M)^{3}$

\subsection{Extraterrestrial solar radiation-based models}

Extraterrestrial solar radiation-based models are employed by solar radiation researchers for estimating global solar radiation as a result of its great important and influence for determining the global solar radiation striking a particular location at the top of the atmosphere and its comprehensive impact on the global solar radiation on the horizontal surface. Thus, the functional form and model employed in Nigeria are presented in this section.

\subsubsection{Group 1}

In this group, clearness index is corrected to extraterrestrial solar radiation $\left(\mathrm{H}_{\mathrm{o}}\right)$ in the form:

$$
H=a+b\left(H_{o}\right)+c\left(H_{o}\right)^{2}
$$

Ugwuoke and Okeke [55] developed the following MB model for Nsukka as:

$$
H=795.9868-193.14123\left(H_{o}\right)+14.57598\left(H_{o}\right)^{2}
$$

\subsection{Hybrid parameter-based models}

As far as the input parameter for estimating global solar radiation on the horizontal surface vary periodically with the local climate in a particular geographical location, it therefore implies that to accurately developed a model that can fit a locality, the solar energy researcher must test the local climate with various input parameters owing to the availability of the meteorological parameters at the disposal of the researcher. Several solar energy researchers in Nigeria and across the globe have observed that hybrid parametersbased models fit local climate more than one variable - sunshinebased, soil temperature-based, extraterrestrial solar radiation-based, cloud cover - based, temperature - based, relative humidity - based 
and precipitation - based models commonly used for estimating global solar radiation. In this section, numerous hybrid parameterbased models are presented and classified based on their input parameters and developing year.

\subsubsection{Group 1}

In this group, sunshine duration and temperature were incorporated with clearness index for estimating global solar radiation in the forms:

$$
\begin{aligned}
& \frac{H}{H_{o}}=a+b\left(\frac{S}{S_{o}}\right)+c\left(T_{\max }\right) \\
& \frac{H}{H_{o}}=a+b\left(\frac{S}{S_{o}}\right)+c\left(T_{\text {mean }}\right) \\
& \frac{H}{H_{o}}=a+b\left(\frac{S}{S_{o}}\right)+c(\sin \delta)+d\left(T_{\text {mean }}\right)
\end{aligned}
$$

Ituen et al. [22] reported the following MB model for Uyo as:

$$
\frac{H}{H_{o}}=1.395+1.591\left(\frac{S}{S_{o}}\right)-0.046\left(T_{\max }\right)
$$

Adekunle and Emmanuel [56] developed the following MB model in Calabar.

$$
\frac{H}{H_{o}}=-11.47+14.03\left(\frac{S}{S_{o}}\right)+0.96(\sin \delta)+0.84\left(T_{\text {mean }}\right)
$$

Akpan and Osu [44] developed the following MB model for Port Harcourt as:

$$
\frac{H}{H_{o}}=-0.194+0.459\left(\frac{S}{S_{o}}\right)+0.014\left(T_{\text {mean }}\right)
$$

\subsubsection{Group 2}

In this group, sunshine duration and relative humidity were incorporated with clearness index for estimating global solar radiation in the form:

$$
\frac{H}{H_{o}}=a+b\left(\frac{S}{S_{o}}\right)+c(R H)
$$

Akpan and Osu [44] developed the following MB model for Port Harcourt as:

$$
\frac{H}{H_{o}}=0.461+0.422\left(\frac{S}{S_{o}}\right)-0.003(R H)
$$

Okundamiya et al. [47] proposed the following MB model for Benin City as:

$$
\frac{H}{H_{o}}=0.6700+0.4381\left(\frac{S}{S_{o}}\right)-0.0046(R H)
$$

\subsubsection{Group 3}

In this group, temperature and relative humidity were incorporated with clearness index for estimating global solar radiation in the forms:

$\frac{H}{H_{o}}=a+b(R H)+c\left(T_{R}\right)+d(\Delta T)$

$$
\begin{aligned}
& \frac{H}{H_{o}}=a+b\left(\frac{\Delta T+R H}{N}\right)^{0.5} \\
& \frac{H}{H_{o}}=a+b\left(\frac{\Delta T+R H}{N}\right)^{0.5}+c\left(T_{R}\right)
\end{aligned}
$$

Kolebaje et al. [51] fitted the following MB models for Ikeja as:

$\frac{H}{H_{o}}=-2.686+0.001(R H)+2.834\left(T_{R}\right)+0.115(\Delta T)$

$\frac{H}{H_{o}}=2.281-0.675\left(\frac{\Delta T+R H}{N}\right)^{0.5}$

$\frac{H}{H_{o}}=3.886-0.673\left(\frac{\Delta T+R H}{N}\right)^{0.5}-2.135\left(T_{R}\right)$

\subsubsection{Group 4}

In this group, minimum and maximum temperature difference and cloud cover were correlated with clearness index in form:

$\frac{H}{H_{o}}=a+b(\Delta T)+c(C)$

Falayi [57] developed the following MB model for Abeokuta as:

$\frac{H}{H_{o}}=7.431885+0.03947(\Delta T)-20.682(C)$

\subsubsection{Group 5}

In this group, minimum and maximum temperature difference and precipitation were incorporated with clearness index for estimating global solar radiation in the form:

$\frac{H}{H_{o}}=a+b(\Delta T)+c(P)$

Falayi [57] developed the following MB model for Abeokuta as:

$$
\frac{H}{H_{o}}=0.09612+0.04234(\Delta T)-0.000072(P)
$$

\subsubsection{Group 6}

In this group, sunshine duration, temperature and relative humidity were incorporated with clearness index for estimating global solar radiation in the form:

$$
\frac{H}{H_{o}}=a+b\left(\frac{S}{S_{o}}\right)+c\left(T_{\max }\right)+d\left(\frac{R H}{100}\right)
$$

Ituen et al. [22] recorded the following MB model for Uyo as:

$$
\frac{H}{H_{o}}=1.387+1.592\left(\frac{S}{S_{o}}\right)-0.045\left(T_{\max }\right)+0.004\left(\frac{R H}{100}\right)
$$

Ogolo [32] developed the following MB model for Akure as:

$\frac{H}{H_{o}}=0.333+0.233\left(\frac{S}{S_{o}}\right)-0.0000537\left(T_{\text {mean }}\right)+0.00017(R H)$

Adekunle and Emmanuel [56] developed the following MB model for Ibadan as:

$\frac{H}{H_{o}}=-34.72-0.14(\sin \delta)+9.82\left(\frac{S}{S_{o}}\right)+0.09\left(R H_{\text {mean }}\right)+1.53\left(T_{\text {mean }}\right)$ 
Akpan and Osu [44] developed the following MB model for Port Harcourt as:

$$
\frac{H}{H_{o}}=0.229+0.403\left(\frac{S}{S_{o}}\right)+0.007\left(T_{\text {mean }}\right)-0.003(R H)
$$

\subsubsection{Group 7}

In this group, sunshine duration, temperature and cloud were incorporated with clearness index for estimating global solar radiation in the form:

$$
\frac{H}{H_{o}}=a+b\left(\frac{S}{S_{o}}\right)+c\left(T_{R}\right)+d\left(T_{\max }\right)+e(C)
$$

Okundamiya et al. [47] developed the following MB model for Benin City as:

$$
\frac{H}{H_{o}}=-0.5700+0.1158\left(\frac{S}{S_{o}}\right)+0.4513\left(T_{R}\right)+0.0285\left(T_{\max }\right)-0.0345(C)
$$

\subsubsection{Group 8}

In this group, cloud cover, relative humidity and precipitation is correlated with clearness index in the form:

$$
\frac{H}{H_{o}}=a+b(C)+c(R H)+d(P)
$$

Falayi [57] developed the following MB model for Abeokuta as:

$$
\frac{H}{H_{o}}=11.1626-28.924(C)-0.00048(R H)-0.00525(P)
$$

\subsubsection{Group 9}

In this group, maximum and minimum temperature difference, relative humidity, cloud cover and precipitation were incorporated with clearness index for estimating global solar radiation in the form:

$\frac{H}{H_{o}}=a+b(\Delta T)+c(R H)+d(P)+e(C)$

Falayi [57] developed the following MB model for Abeokuta as:

$$
\begin{aligned}
& \frac{H}{H_{o}}=0.52479+0.01475(\Delta T) \\
& +0.0001(R H)+0.003389(P)-000187(C)
\end{aligned}
$$

\subsubsection{Group 10}

In this group, sunshine duration, temperature and precipitation were incorporated with clearness index for estimating global solar radiation in the forms:

$$
\begin{aligned}
& \frac{H}{H_{o}}=a+b\left(T_{\text {mean }}\right)+c(P)+d\left(\frac{S}{S_{o}}\right) \\
& \frac{H}{H_{o}}=a+b\left(\frac{S}{S_{o}}\right)+c\left(T_{\text {min }}\right)+d(P)
\end{aligned}
$$

Okonkwo and Nwokoye [31] developed the following MB model for Minna.

$$
\frac{H}{H_{o}}=0.392+0.330\left(\frac{S}{S_{o}}\right)-0.004\left(T_{\min }\right)-0.003(P)
$$

Ogolo [32] reported the following MB model for Nigeria as:

$$
\frac{H}{H_{o}}=0.363-0.00170\left(T_{\text {mean }}\right)-0.000151(P)+0.375\left(\frac{S}{S_{o}}\right)
$$

\subsubsection{Group 11}

In this group, sunshine duration, temperature, relative humidity and precipitation were incorporated with clearness index for estimating global solar radiation in the forms:

$\frac{H}{H_{o}}=a+b\left(\frac{S}{S_{o}}\right)+c(P)+d(R H)+e\left(T_{R}\right)$

$\frac{H}{H_{o}}=a+b(R H)+c(T)+d(P)+e\left(\frac{S}{S_{o}}\right)$

Okonkwo and Nwokoye [48] developed the following MB model for Minna as:

$\frac{H}{H_{o}}=0.501+0.260\left(\frac{S}{S_{o}}\right)-0.004(P)+0.070(R H)-0.328\left(T_{R}\right)$

Akpan and Osu [44] developed the following MB models for Port Harcourt as:

$$
\frac{H}{H_{o}}=0.347-0.002(R H)+0.002(T)-0.001(P)+0.365\left(\frac{S}{S_{o}}\right)
$$

\subsubsection{Group 12}

In this group, sunshine duration, temperature, relative humidity, wind and precipitation were incorporated with clearness index for estimating global solar radiation in the form.

$$
\frac{H}{H_{o}}=a+b\left(\frac{S}{S_{o}}\right)+c(P)+d(W)+e(R H)+f\left(T_{R}\right)
$$

Okonkwo and Nwokoye [48] developed the following MB model for Minna as:

$$
\frac{H}{H_{o}}=0.513+0.244\left(\frac{S}{S_{o}}\right)-0.005(P)+0.002(W)+0.082(R H)-0.328\left(T_{R}\right)
$$

\subsubsection{Group 13}

In this group, sunshine duration, temperature, relative humidity, latitude and day number in the year (n) were incorporated with global solar radiation $(\mathrm{H})$ in the form.

$$
\begin{aligned}
& H=a \cos \varphi+b \cos n+c\left(T_{\text {max }}\right)+d\left(\frac{S}{S_{o}}\right)+e\left(\frac{S}{S_{o}}\right)^{3}+f\left(\frac{T_{\text {max }}}{R H}\right)+ \\
& g\left(\frac{T_{\text {max }}}{R H}\right)^{2}+h\left(\frac{T_{\text {max }}}{R H}\right)^{3}+i\left(\frac{T_{\text {max }}}{R H}\right)^{4}+j(\cos \varphi \cos n)+k\left(\frac{T_{\text {max }}}{\cos \varphi}\right)+
\end{aligned}
$$

$l \cos ^{2} n+m$

Ajayi et al. [58] calibrated the following MB model for Nigerian environment as: 
$+7.0114\left(T_{\max }\right)+110.16\left(\frac{S}{S_{o}}\right)+$

$30.619\left(\frac{S}{S_{o}}\right)^{3}-184.1\left(\frac{T_{\max }}{R H}\right)+154.08\left(\frac{T_{\max }}{R H}\right)^{2}$

$-52.038\left(\frac{T_{\max }}{R H}\right)^{3}+$

$6.048\left(\frac{T_{\max }}{R H}\right)^{4}-3.2879(\cos \varphi \cos n)$

$-5.0832\left(\frac{T_{\max }}{\cos \varphi}\right)-0.0348 \cos ^{2} n+$

13.852

\section{Soft computing method}

The artificial intelligence and computation intelligence approaches such as Radial basis function Network (RBFN), Support Vector Machine (SVM), Genetic Algorithm (GA), Multilayer perceptron Neural Network (MLP), Artificial Neuro-fuzzy inference system (ANFIS) and Hybrid Network have been widely used in several scientific areas for modeling, estimation, prediction and optimization such as automatic relevance determination (ARD) methodology, the niching genetic algorithms, and the adaptive neuro-fuzzy inference system (ANFIS) technique can be adopted for estimating global solar radiation in Nigeria. Numerous application of artificial neural networks are reported in various fields such image impression, defense, mathematics, character recognition, aerospace, neurology, meteorology, economics, electronic nose engineering, medicine and psychology. These approaches have been employed for prediction and empirical analysis in market trend forecasting, solar and weather.

\subsection{Artificial neural network}

Artificial neural network is a numerical estimation approach that developed in the last decades. It is inspired by biological neural system, and it has the capacity to process non-linear relationship, data sorting, pattern detection, optimization, clustering and simulation. It is equally known as "black box" modeling technique because it does not present physical explanation of the question. In terms of configuration, an ANN model usually contains input layer, hidden layer and output layer. In terms of the process of data manipulation, it mainly consists of two stages: training section and testing section. In training section, the ANN finishes learning and storing the pattern information of existing database. In testing section, the ANN recalls the information to produce output data based on particular input database. The calculation units of ANN are interconnected neurons in the layers as shown in Fig. 2. Due to the technicalities involved in artificial neural network (ANN), few solar-energy researchers have employed this approach for estimating global solar radiation in Nigeria. The structure of ANN is characterized by its input layer, one or more hidden layer and output layer. This section reveals a number of solar-energy estimation using ANN.

Ibeh and Agbo [59] employed Angstrom-Prescott and Multilayer perception Neural Network models to estimate mean monthly global solar radiation on a horizontal surface based on meteorological parameters such as maximum temperature, relative humidity, cloudiness and sunshine duration for Warri, Nigeria from 1991 to 2007 as presented in Fig. 3 and Table 4. In order to compare the performance of ANN model and Angstrom-Prescott model, statistical analysis applying Mean bias error (MBE),Root mean square error (RMSE) and Mean percent error (MPE) have been taken. The comparison between the ANN model and Angstrom-Prescott empirical models have shown the superiority of the ANN model and the shape of Fig. 3 further proves the relationship between predicted and actual values. The result has confirmed the application of the ANN model in the prediction of solar radiation and shows that ANN model predicts better than other models.
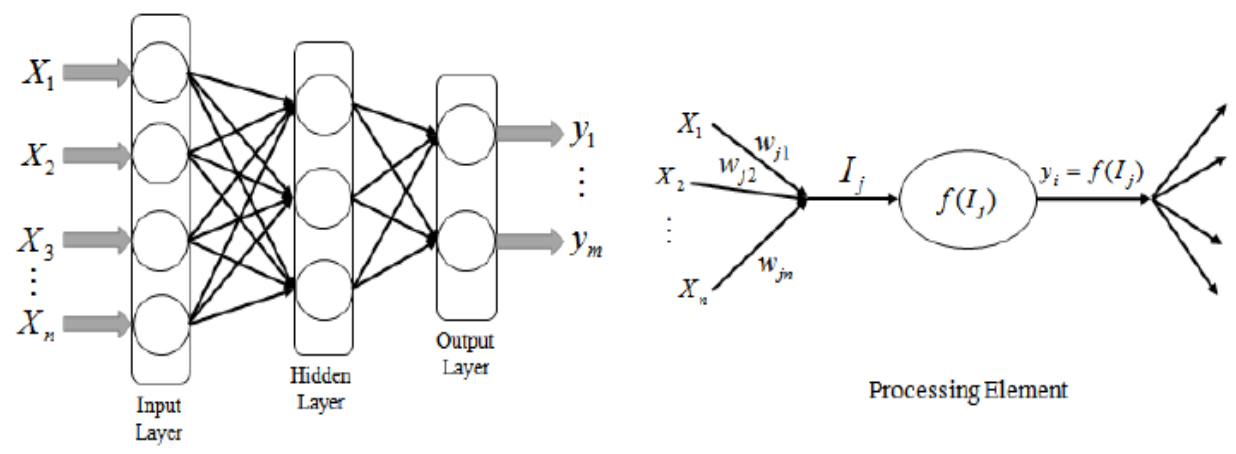

ArtificialNeural Network

Fig. 2: Schematic Diagram of a Processing Element (Right Side) and an Artificial Neural Network (Left Side).

Table 4: Comparison between Measured and Estimated data using ANN and Empirical Models (Ibeh and Agbo [59])

\begin{tabular}{llllll}
\hline Model & $\mathrm{R}$ & $\mathrm{R}^{2}$ & MBE & RMSE & MPE \\
\hline ANN & 0.979 & 0.958 & 0.0625 & 0.050106 & -84.3124 \\
Empirical & 0.951 & 0.904 & -0.3675 & 3.39118 & -80.3875 \\
\hline
\end{tabular}

Ibeh et al. [60] used multiple regression and ANN models to estimate global solar radiation in Warri from 1991-2007 as shown in Table 5 and Fig. 4. The statistical results and graph analysis show that MLP network (ANN) has the minimum forecasting error and can be considered as a better model to estimate global solar radiation in Warri.
Ibeh et al. [61] applied Multilayer perceptron Neural Network model and some existing empirical models to estimate mean monthly global solar radiation on horizontal surface based on sunshine duration for Minna, Nigeria from 1987 to 1991 as presented in Fig. 5. In order to compare the performance of ANN model and the measured data, statistical analysis using Mean biaserror (MBE), 
Root mean square error (RMSE) and Mean percent error (MPE) have been taken. The results clearly show that other models have predicting capacity, but ANN model can better predict the global solar radiation at Minna.

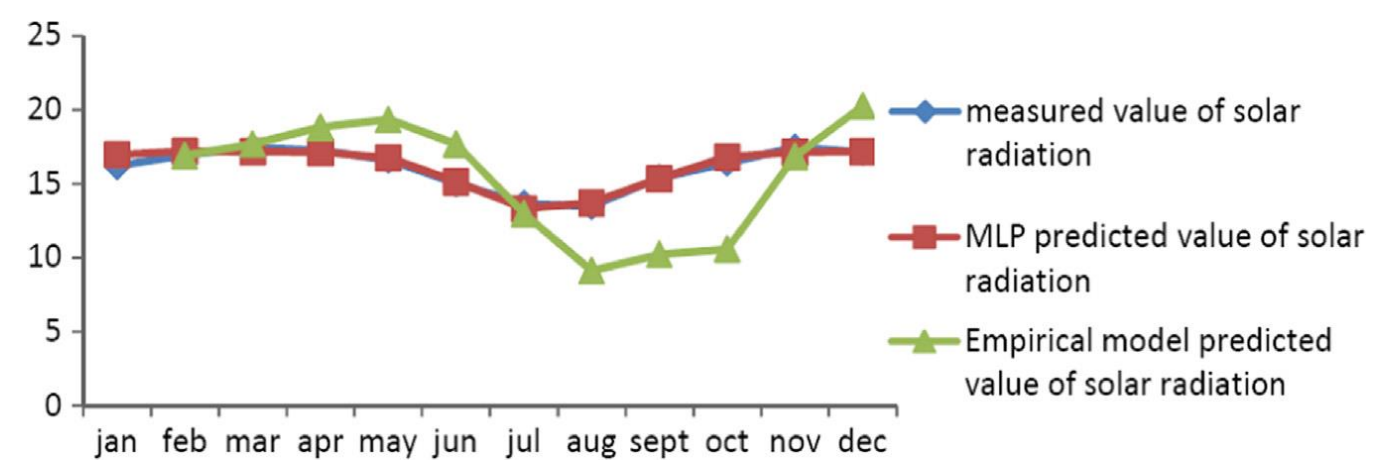

Fig. 3: Comparison Between Measured, MLP Predicted and Empirical Model Predicted of Solar Radiation (Ibeh and Agbo [59]).

\begin{tabular}{lccc} 
& Table 5: Comparison between Measured Solar Radiation, Regression Values Solar Radiation and ANN (Ibeh Et Al. [60]) & MPE \\
\hline Model & MBE & RMSE & -1.2580 \\
& & 0.0004 & -2.2116 \\
ANN & 0.0085 & 0.0104 & \\
Regression & 0.2490 &
\end{tabular}

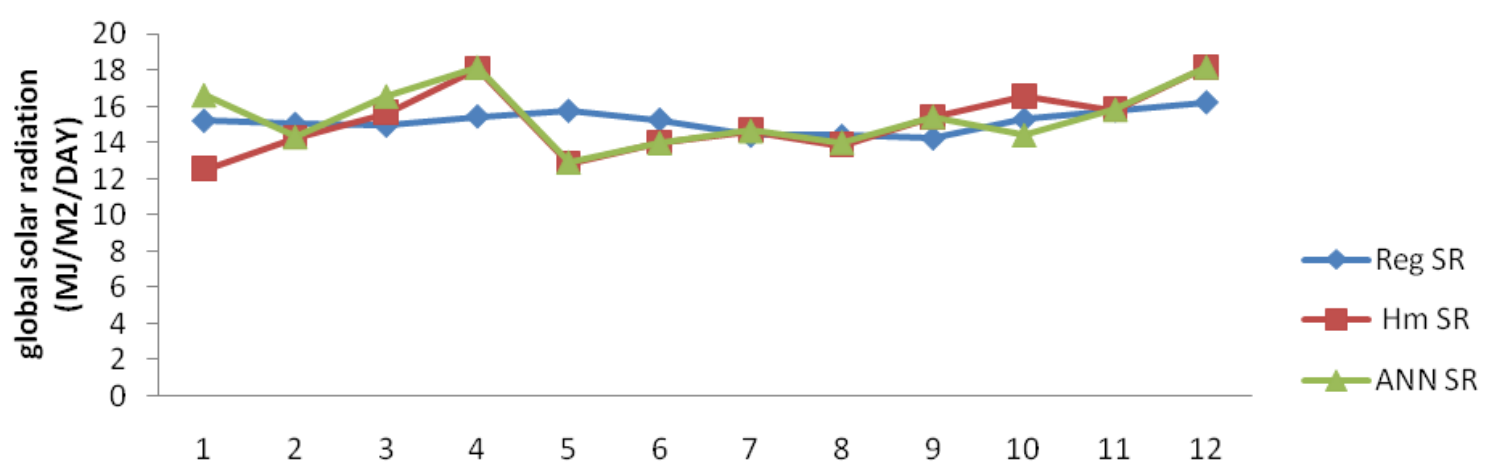

Fig. 4: Comparison of Measured Solar Radiation, Regression Values of Solar Radiation and Artificial Neural Network (Ibeh Et Al. [60]).

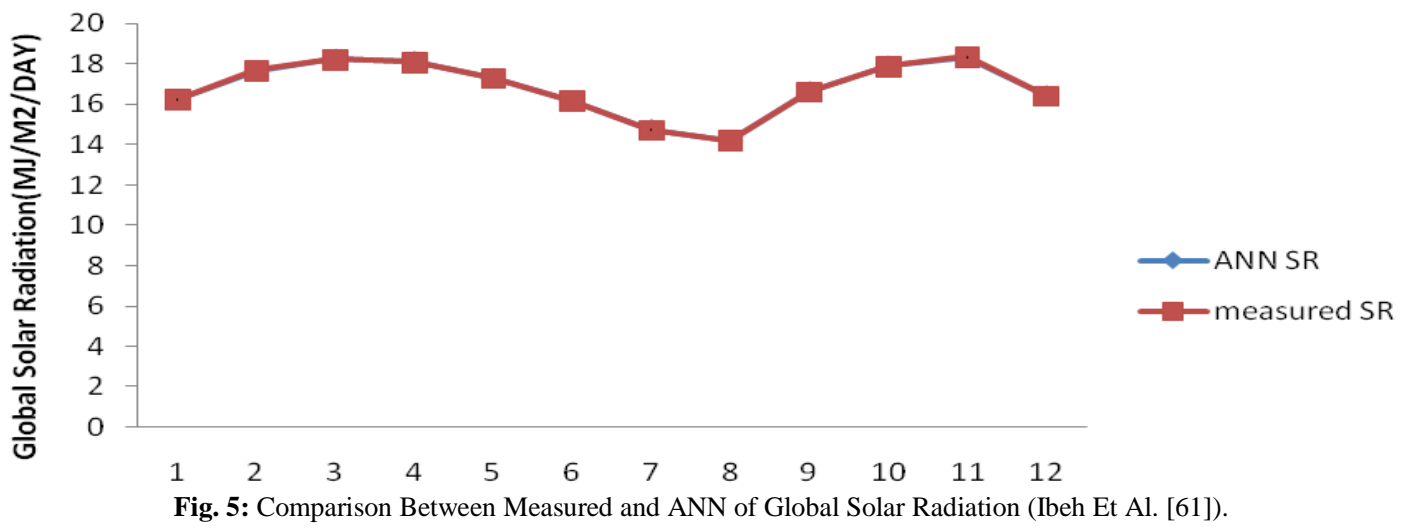

Ibeh et al. [62] employed ANN and Angstrom-Prescott model to estimate the monthly average daily global solar radiation on a horizontal surface for Uyo city in Nigeria. Fig. 6 and Table 7 show the comparison between measured, ANN and Angstrom-Prescott value of the monthly mean daily global solar radiation on a horizontal surface. From the Figure 6 and Table 6 as mentioned earlier, it is clear that ANN model has strong agreement and relationship with the measured monthly mean daily global solar radiation on a horizontal surface at the site.

Table 6: Comparison between Measured and Estimated Data Using ANN and Empirical Models (Ibeh et al. [62])

\begin{tabular}{lll}
\hline Model & $\mathrm{R}$ & $\mathrm{R}^{2}$ \\
\hline ANN & 0.987 & 0.974 \\
Empirical & 0.870 & 0.757 \\
\hline
\end{tabular}

Agbo et al. [63] employed empirical and ANN models for estimation of global solar radiation at Onitcha (1996-2006) applying mean relative humidity and mean temperature as input variables. Based on the validation results presented in Table 8, it therefore becomes clear that artificial neural network has better agreement with measured global solar radiation at the location.

Chukwu and Nwachukwu [64] applied mean daily sunshine hours, maximum temperature, cloud cover and relative humidity parameters to estimate global solar radiation at Makurdi using ANN model and some existing empirical models. The result shown in Table 8 indicates that the comparison between the ANN model and some existing empirical models showed the advantage of ANN model prediction.

Sanusi et al. [69] applied day number, month number, daily mean air temperature, relative humidity, sunshine hours to develop four ANN following combination of input variables (MLP-1, MLP-2, MLP-3 and MLP-4 for Sokoto with some existing models. The results in Table 9 revealed that ANN model could reasonably estimate global solar radiation in Sokoto compared to empirical models. 


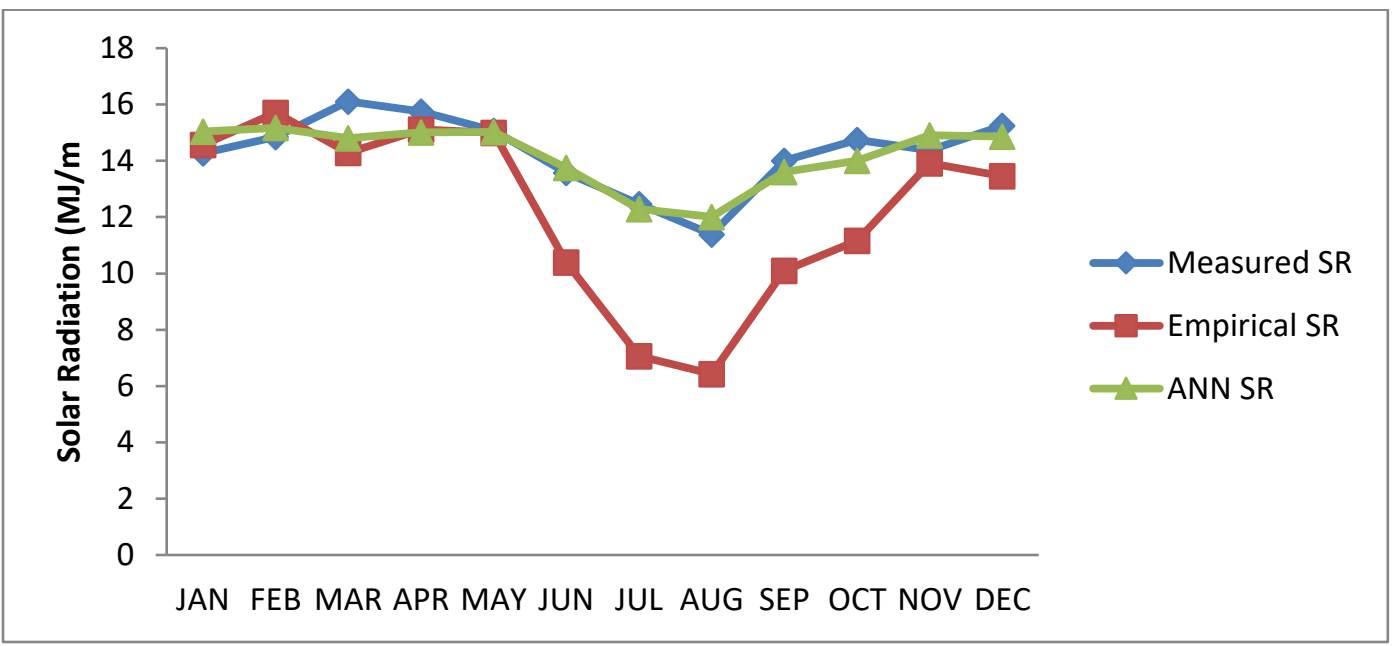

Fig. 6: Comparison of Measured Solar Radiation, Regression Values of Solar Radiation and Artificial Neural Network (Ibeh et al. 2012c)

Table 7: Comparison between Measured Solar Radiation, Empirical Values of Solar Radiation and ANN (Agbo et al. [63])

\begin{tabular}{|c|c|c|c|}
\hline Model & $\mathrm{MBE}$ & RMSE & MPE \\
\hline ANN & 0.00024 & 0.0134 & 0.203 \\
\hline Empirical 1: (Relative Humidity; One Variable) & 0.0032 & 0.0109 & -0.753 \\
\hline Empirical 2: (Temperature; One Variable) & 0.087 & 0.3025 & -0.778 \\
\hline Empirical 3: (Relative Humidity and Temperature; Two Variables) & 0.350 & 1.214 & 3.928 \\
\hline
\end{tabular}

Table 8: Comparison between Measured and Estimated Data Using ANN and Empirical Models (Chukwu and Nwachukwu, 2012)

\begin{tabular}{|c|c|c|c|}
\hline Model & $\mathrm{R}^{2}$ & RMSE & MPE \\
\hline Angstrom-Prescott-Page & 0.2600 & 0.0820 & 22.3759 \\
\hline Bamiro [65] & 0.3500 & 0.0768 & 21.2233 \\
\hline Swartmaann-Ogunlade [66] & 0.6766 & 0.0543 & 16.3304 \\
\hline Burari and Sambo [67] & 0.7710 & 0.0456 & 12.8941 \\
\hline Augustine and Nnabuchi [68] & 0.8410 & 1.5640 & 0.0770 \\
\hline ANN & 0.9982 & 0.0032 & 0.8212 \\
\hline
\end{tabular}

Table 9: Comparison between Measured and Estimated Data Using ANN and Empirical Models (Sanusi et al. [69])

\begin{tabular}{|c|c|c|c|c|}
\hline Model & MBE & RMSE & MPE & $\mathrm{R}^{2}$ \\
\hline MPL-1 & 0.167 & 0.295 & -7.724 & 0.950 \\
\hline MPL-2 & 0.103 & 0.288 & -4.177 & 0.959 \\
\hline MPL-3 & 0.856 & 2.117 & -39.526 & 0.545 \\
\hline MPL-4 & 0.248 & 0.901 & -11.948 & 0.931 \\
\hline Angstrom-Prescott & -0.244 & 4.655 & -0.3549 & 0.909 \\
\hline Hargreaves and Samani [53] & -0.022 & 0.119 & -0.1975 & 0.946 \\
\hline
\end{tabular}

Egeonu et al. [70] employed temperature based, artificial neural network (ANN) models and Angstrom type models for predicting global solar radiation for selected locations in Nigeria. The ANN models were standard multi-layered feed forward, back-propagation neural networks trained with the Levenberg Marquardt algorithm using seventeen years data collected from Nigerian Meteorological Agency (NIMET), Abuja, Nigeria and tested with twentytwo years monthly averaged data downloaded from National Aeronautical Space Administration (NASA) online database. The network inputs were latitude, longitude, altitude, month, maximum and minimum ambient temperature, while monthly mean global solar radiation was the network output. The Angstrom type empirical models correlated global solar radiation with minimum and maximum ambient temperatures. The performances of the models were evaluated using statistical performance indicators, namely RMSE, MBE, $\mathrm{R}^{2}$ and rank score. The coefficients of determination $\left(\mathrm{R}^{2}\right)$ of the ANN models were always greater than $99 \%$ for all the selected locations while the highest coefficient of determination for the empirical models was $89 \%$. The temperature-based ANN models were thus shown to deliver superior and more reliable outcomes in comparison with the empirical models.

\subsection{Artificial neuro-fuzzy inference system (ANFIS)}

The ANFIS is a multilayer feed-forward network, which applies neural network learning algorithms and fuzzy reasoning to map in- puts into an output. The combination of least squares and back propagation algorithm gives rise to this multilayer feed-forward network (ANFIS) for estimation of activation function. ANFIS is principally dependent on conventional mathematical tools that combine the properties of fuzzy logic and neural networks to form a hybrid intelligent system. It increases the capacity to learn and adopt automatically. The structure of ANFIS model is shown in Fig. 7. There are five layers for ANFIS, including fuzzification, rules, normalization, defuzzification and summation.

Olatomiwa et al. [71] analysed ANFIS for Iseyin, Nigeria using inputs such as maximum temperature, minimum temperature and sunshine hours. 15 years data was employed to train the model while 6 years of data was applied for testing. The ANFIS results are compared with experimental results using root-mean-square error (RMSE) and coefficient of determination $\left(\mathrm{r}^{2}\right)$. The results signify an improvement in predictive accuracy and ANFIS capability to estimate solar radiation. The statistical characteristics of RMSE 1.0854 and $\mathrm{R}^{2} 0.8544$ were obtained in the training phase and RMSE 1.7585 and $\mathrm{R}^{2} 0.6567$ in the testing phase. As a result, the proposed model deemed an efficient technique to predict global solar radiation for practical purposes compared to existing techniques as shown in Table 10. 


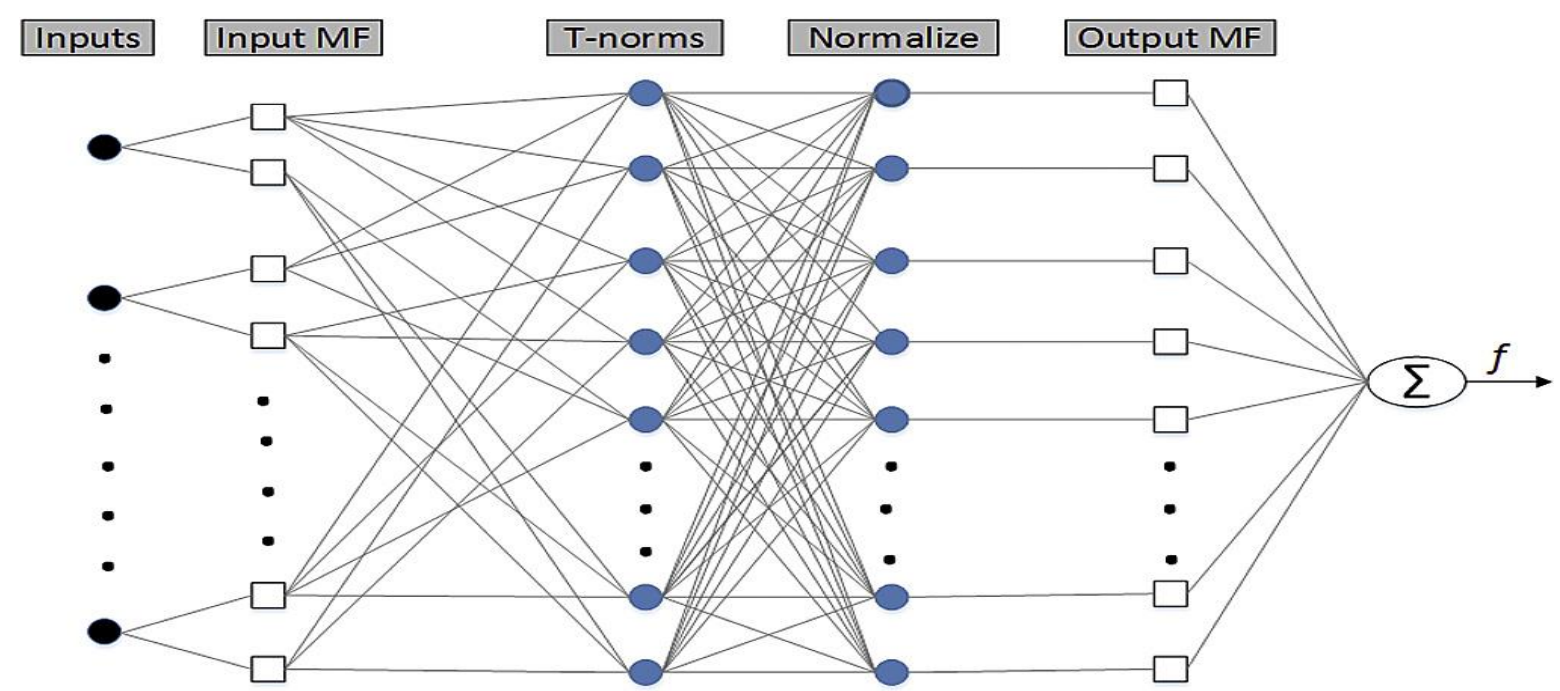

Fig. 7: The General Structure of ANFIS Model (Zou Et Al., 2017).

Table 10: Comparison between Measured and Estimated Data Using Ann and Empirical Models (Olatomiwa Et Al., 2015)

\begin{tabular}{lllll}
\hline References & Model Type & Input parameters & Country & \\
\hline Angstrom Model [16] & Empirical & 3 & - & $\mathrm{R}^{2}$ \\
Yohanna et al. [72] & Empirical & 3 & Nigeria & 0.780 \\
Abdalla [73] & Empirical & 5 & Bahrain & 0.608 \\
Bahel et al. [74] & Empirical & 3 & Bahrain & 0.780 \\
Bakirik [75] & Empirical & 3 & Turkey & 0.790 \\
Ramedani et al. [76] & ANN & 7 & Iran & 0.780 \\
Ramedani et al. [76] & ANFIS & 7 & Iran & 0.799 \\
Olatomiwa et al. [71] & ANFIS & 3 & Nigeria & 0.808 \\
\hline
\end{tabular}

\subsection{Autoregressive moving average}

Autoregressive moving model assumes the values of prediction as a random sequence that only changes with time, which is equally called time series model. This model is applied to predict global solar radiation when the meteorological condition will be considered.

Ayedele and Ogunjunjuyigbe [38] employed a probability function to represent the distribution of clearness index in a year. The coefficients were determined by applying 7 years daily global solar radiation data. Thereafter, the authors inversely transformed the probability function to obtain the estimation of clearness index. No other input parameter was recorded and in the model, and from the theory, the author surmised that the estimation is for long-term monthly average global solar radiation (daily data). Besides the month of October, the performances of other months were excellent. The mean RMSE was $0.383 \mathrm{MJ} / \mathrm{m}^{2} /$ day and the average MPE was $2.00 \%$. They equally calculated three (3) empirical models and obtained their coefficients for each month. On the whole, the performances of these four models were similar, such as for January, the RMSE of them ranged from 0.213 to $0.221 \mathrm{MJ} / \mathrm{m}^{2} /$ day as shown in Table 11 .

Table 11: Comparison between Measured and Estimated Data Using ANN and Empirical Models (Ayedele and Ogunjunjuyigbe [38]

\begin{tabular}{llll}
\hline References & RMSE & MPE & $\mathrm{R}^{2}$ \\
\hline Angstrom [16-17] & $0.220-2.63$ & $1.913-7.443$ & $0.689-0.985$ \\
Garcia [54] & $0.217-1.359$ & $1.912-6.978$ & $0.735-0.978$ \\
Hargreaves [53] & $0.199-2.38$ & $2.018-7.985$ & $0.799-0.983$ \\
Ayedele [38] & $0.192-1.271$ & $1.727-5.101$ & $0.781-0.989$ \\
\hline
\end{tabular}

\section{Discussion}

Numerous theoretical model published and validated by peers and researchers for estimating global solar radiation in Nigeria is relatively high, which makes it difficult to select the best approach for a particular site. Besharat et al. [5] classified various global solar radiation models into four categories (sunshine-based, cloud-based, temperature-based models and other meteorological parameterbased models). Peers and researchers have to revealed that sunshine-based models are often employed probably because of its global availability at most weather stations, temperature-based models can be a conveniently used if calibrated for a particular locality, cloud cover and soil temperature-based models can be used as an alternative but are sensible to human biasing, monthly-based models can be applied comfortable because of the constant movement of the earth on its axis thereby culminating into constant variations from one month to another, extraterrestrial solar radiationbased models can be adopted with ease since it has major influence in determining the amount of irradiation that falls in a given location, and hybrid parameter-based models are reported to estimate the global solar radiation on a horizontal surface with a high precision, but most of their input parameters are not readily available at most locations of interest [5], [22], [38], [44], [46], [55], [56], [57].

In this comparative review, the author has added four meteorological parameters often used by researchers in Nigeria for estimating global solar radiation based on its availability in Nigerian weather stations via: monthly-based model, extraterrestrial-based model, relative humidity-based model and precipitation-based model. In general, 33 empirical models were reported from the review, 8 ANN models, 1 ANFIS model, and 1 auto regressive moving average method from the review.

From the review, it was observed that, it is impossible to introduce a set of input parameter with a particular functional form for optimal estimation of global solar radiation for Nigeria. In fact, the tendency of enhancing the accuracy of estimation by employing some sets of input parameters is solely dependent on local climate and site. This could be attributed to the specific nature of global solar radiation, which is totally dependent upon the local climate as well as geographical location. To restate this, a brief review of the effort of researchers in Nigeria to enhance the accuracy of estimation of global solar radiation is represented in the following.

Boluwaji and Onyedi [46] employed sunshine-based model and temperature-based model for estimation of global solar radiation in Kano, Kaduna and Sokoto by incorporating both models; it was observed that the new model shown better performance over either 
sole sunshine-based or sole temperature-based models. Okundamiya et al. [47] reported that inclusion of cloud cover as an input parameter improved the accuracy over multiple meteorological inputs parameters such as sunshine duration, temperature and relative humidity used for estimating global solar radiation in Nigeria. Falayi [57] observed that incorporating sunshine-based model, temperature-based model and relative humidity-based model yielded better precision than over either sole sunshine-based model, temperature-based model, or relative humidity-based model for several locations in Nigeria. This result is comparable to the report of other researchers in Nigeria Ituen et al. [22], [32], [44].

Ajayi et al. [58] revealed that previous studies in Nigeria did not include the latitude as an input parameter as a result, their accuracy and applications were limited to the site from which the models were developed. Hence, inclusion of latitude is much fewer sites dependent and capable to capture the differences due to changes in geographical locations. This is in agreement with the report of Ogolo [32] who observed that both climatologically and geographical factors should be considered significant in the development of any scheme for the simulation of global solar radiation in Nigeria after developing thirty models with various input parameters over six tropical ecological zones in Nigeria. Ajayi et al. [58] further reported that inclusion of relative humidity and temperature as input variables to existing sunshine-based models makes the model much more sensitive to climatic and weather changes in Nigeria. They equally pointed out that including cosine of the day number of the year makes it possible for global solar radiation distribution that is symmetrical about the middle of the year when the rainy season peaks, with an increasing global solar radiation profile towards December, and backwards towards January.

From the previous studies, clearly from above findings that introducing an appropriate set of an input parameters for global solar radiation prediction in any location of interest is not a viable discovery. This is as a result of its complexity because of using numerous numbers of required input's parameters; inaccuracies associated with irrelevant parameters, difficulty in explaining the model and time-consuming task for collecting the needed variable.

However, the soft computing methods broadly employed in numerous scientific fields for modeling, prediction and optimization such as automatic relevance determination (ARD) methodology, the niching genetic algorithms, and the adaptive neuro-fuzzy inference system (ANFIS) technique can be adopted for estimating global solar radiation in Nigeria. For example, Ayedele and Ogunjunjuyigbe [38] applied auto regressive moving average method and recorded more accurate performance compared to empirical models Angstrom-Pescott [16-17]; Garcia [54]; Hargreaves and Samani [53] for Ibadan. Sanusi et al. [69] used ANN models to estimate global solar radiation in Sokoto, Nigeria and observed that their model performed better statistically when compared to existing empirical models in literature Angstrom [16]; Hargreaves and Samani [53] Chukwu and Nnachukwu [64] used artificial neural network (ANN) method for estimating global solar radiation for Makurdi and observed that their approach (ANN) yielded better performance over researchers that employed empirical model's Angstrom- Prescott [16-17]; Bamiro [65]; Swartmaann-Ogunlade, [66]; Burari and Sambo [67]; Augustine and Nnachukwu [68]. Olatomiwa et al. [71] reported better performance using ANFIS method for Iseyin, Nigeria compared to several researchers that used empirical models Yohanna et al. [72]; Abdalla [1994]; Bahel et al. [74]; Bakirik [75] ANN models Ramediani et al. [76]; and ANFIS method Ramediani et al. [76]. Ibeh et al. [61] calibrated better performance employing ANN approach over existing empirical models Glover et al. [77]; Bahel et al. [74]; Rietveld, [19]; Allen et al. [78] for Warri, Nigeria. The comparison in this section can be seen in Tables 3, 6-9.

The global Solar Radiation empirical models examine in the current paper is distinctive and provide valuable outcome for various circumstances. The models regarded as capable and convenient for daily and monthly prediction are sunshine-based models, temperature-based models, relative humidity-based models, cloud-coverbased models, precipitation-based models and hybrid parameter- based models. A number of significant aspects identified in literature as well as shortcomings with solutions recommended in the present work are summed up subsequently.

The mean percentage error (MPE), mean bias error (MBE), root mean square error (RMSE) and correlation coefficient $\left(\mathrm{R}^{2}\right)$ empirical models. Certain standard error proposed estimation metrics are requisite for multiple model comparisons in performance assessment. Numerous research works used their individual error metrics to yield global solar radiation estimation outcomes. In literature, the most favoured and commonly employed parameters to obtain straight forward, suitable evaluation and mean absolute error, as well as normalized and root mean square errors. This evaluation metrics can be adopted for making a simple and acceptable evaluation by solar-energy researchers in Nigeria.

In the light of the presented literature, it seems that a number of sites do not have meteorological stations, whereby empirical and counting models should be developed using the latitude, altitude, longitude and extraterrestrial radiation inputs for precise measurement. Soft computing models have newly been initiated for estimating renewable-energy resources, but additional work is necessary to increase solar radiation prediction accuracy pertaining to numerous seasons, climate change and poor weather, on different surfaces, e.g. tiled. Hence, the greatest advantages may be acquired from natural resources to supply increasingly reliable efficient solar systems on the market.

\section{Concluding remarks}

This paper presents a quantitative review of literature on Global Solar Radiation global solar radiation in Nigeria. 145 empirical models and 42 functional forms were obtained employing sunshine-base models, temperature-base models, precipitation-base models, monthly-based models, extraterrestrial solar radiation-based models, cloud core-base models, relative humidity-base models and hybrid parameter-base models. The findings in our research provide future dimensions to industry and research practitioners for further studies on solar system and global solar radiation estimation.

Soft computing models are found to estimate global solar radiation accurately in different climate conditions across the globe. This can be attributed to the fact that these models can accept many input parameters as compared to empirical models that strengthen its reliability. Moreover, it can also be concluded that soft computing models estimations offer greater accuracy as compared to empirical models, e.g. Tables 4-10 and Figures, 3-6 show estimation error is a range (less than 20\%), and this could be very good in terms of global solar radiation estimation. Therefore, soft computing models are much more demanding in the domain of renewable-energy resource estimation, such as solar radiation estimation and solar system design. It is finally recommended that future studies on GSR estimation should consider the soft computing techniques in order to achieve better results.

As a result of this review, it can be said that soft computing techniques increase the estimation accuracies in monthly and daily global solar radiation estimation respectively. It is determined that there is a need for further research using soft computing and its applications in Nigeria. The promising results obtained from the soft computing may help industry to benefit from the use of soft computing techniques in Nigeria and the world at large. Thus, the information provided in this research would be highly beneficial to the researchers working in the field of solar radiation estimation.

\section{Nomenclature}

MODIS Moderate-Resolution Imagining Spectroradiameter $\mathrm{H} \quad$ Global solar radiation on the horizontal surface $\left(\mathrm{MJ} / \mathrm{m}^{2} \mathrm{day}\right)$

$\mathrm{DB}$

$\mathrm{K}_{\mathrm{t}}$

$\mathrm{H}_{\mathrm{o}}$

Isc
Daily mean basis

Cleanness index

Extraterrestrial solar radiation $\left(\mathrm{MJ} / \mathrm{m}^{2}\right.$ day $)$

Solar constant $\left(1367 \mathrm{w} / \mathrm{m}^{2}\right)$ 


\begin{tabular}{|c|c|}
\hline S & Sunshine duration (h) \\
\hline $\mathrm{S}_{\mathrm{o}}$ & Daily maximum possible sunshine duration (h) \\
\hline Tmean & Mean temperature $\left({ }^{\circ} \mathrm{C}\right)$ \\
\hline Tmax & Maximum temperature $\left({ }^{\circ} \mathrm{C}\right)$ \\
\hline Tmin & Minimum temperature $\left({ }^{\circ} \mathrm{C}\right)$ \\
\hline TR & Temperature ratio \\
\hline$\Delta \mathrm{T}$ & Difference between maximum and minimum \\
\hline tempera & \\
\hline RH & Relative Humidity (\%) \\
\hline $\mathrm{C}$ & Cloud cover $(\%)$ \\
\hline $\mathrm{n}$ & Mean faction cloud cover or cloudiness index \\
\hline $\mathrm{n}_{\mathrm{n}}$ & \\
\hline $\mathrm{P}$ & Mean precipitation $(\mathrm{mm})$ \\
\hline $\mathrm{W}$ & Mean wind speed $(\mathrm{m} / \mathrm{s})$ \\
\hline $\mathrm{n}$ & day number in the year \\
\hline ANN & Artificial Neural Network \\
\hline ANFIS & Adaptive Neuro-fuzzy inference system \\
\hline ARD & Automatic Relevance Determination \\
\hline \multicolumn{2}{|c|}{ ELM extreme learning machine } \\
\hline \multicolumn{2}{|l|}{$\mathrm{K}$ shape } \\
\hline \multicolumn{2}{|c|}{$\mathrm{R}$ coefficient of correlation } \\
\hline \multicolumn{2}{|c|}{$\mathrm{R}^{2}$ coefficient of determination } \\
\hline \multicolumn{2}{|c|}{ RMSE root mean square error $\left(\mathrm{MJ} / \mathrm{m}^{2}\right.$ day $)$} \\
\hline \multicolumn{2}{|c|}{ MBE mean bias error $\left(\mathrm{MJ} / \mathrm{m}^{2}\right.$ day $)$} \\
\hline \multicolumn{2}{|c|}{ MPE mean percentage error } \\
\hline \multicolumn{2}{|c|}{ RBEN radial basis function network } \\
\hline \multicolumn{2}{|c|}{ GA genetic algorithm } \\
\hline \multicolumn{2}{|c|}{ MLP multilayer perceptron neural network } \\
\hline WT & \\
\hline
\end{tabular}

\section{Greek letters}

$\begin{array}{ll}\delta & \text { Solar declination }\left(^{\circ}\right) \\ \varphi & \text { Latitude of the location }\left(^{\circ}\right) \\ \omega_{s} & \text { Mean sunrise hour angle for the given month } \\ \left({ }^{\circ}\right) & \end{array}$

\section{Acknowledgements}

My thanks go to all the authors cited in this paper for their research works that has made this research possible.

\section{Funding}

This research did not receive any specific grant from funding agencies in the public, commercial, ornot-for-profit sectors.

\section{References}

[1] International Energy Agency) (2015a), Energy and Climate Change World Energy Outlook Special Report, OECD/IEA, Paris, www.worldenergyoutlook.org/energyandclimatechange

[2] H. Khorasanizadeh, G. Mohammadi, Renewable and Sustaining Energy Reviews $53 \quad$ (2016) 338-362. https://doi.org/10.1016/j.rser.2015.08.037.

[3] M. Thirugnanasasambandam, S. Iniyan, A. Goic, Renewable and Sustainable Energy Reviews $14 \quad$ (2010) 312-322. https://doi.org/10.1016/j.rser.2009.07.014.

[4] K.R. Ullah, R. Saidur, H.W. Ping, R.K. Akikur, N.H. Shuvo, Renewable and Sustainable Energy Review 24 (2013) 499-513. https://doi.org/10.1016/j.rser.2013.03.024.

[5] F. Besharat, A. Dehghan, A.R. Faghih, Renewable and Sustainable $\begin{array}{llll}\text { Energy } & \text { Review } & 21 & \text { (2013) }\end{array}$ https://doi.org/10.1016/j.rser.2012.12.043.

[6] B. Yaniktepe,Y.A. Gene, International Journal of Hydrogen 40 (2015) 15278-15283 https://doi.org/10.1016/j.ijhydene.2015.02.064.

[7] J.L. Souza G.B. Lyra, C.M.D. Sanobs, , R.A. Feneiru, C. Tibu, G.B. Lyra, M.A.M. Lemes, Sustainable Energy Technol. Assess. 14 (2016) 35-45. https://doi.org/10.1016/j.seta.2016.01.002.
[8] H. Li, X. Bu, Z. Long, L. Zhao, W. Ma, Energy 44 (2012) 611-615. https://doi.org/10.1016/j.energy.2012.05.033.

[9] T. Muneer, S. Munawwar, Journal of Solar Energy Engineering 128 (2006)104-117. https://doi.org/10.1115/1.2148972.

[10] C. Ertekin, O. Yaldiz, Renewable Energy 17 (1999) 95-102. https://doi.org/10.1016/S0960-1481(98)00109-8.

[11] S.C. Nwokolo, J.C. Ogbulezie, C.K. Toge, S.A. John-Jaja, New York Science Journal 9 (2016a) 40-55

[12] S.C. Nwokolo, J.C. Ogbulezie, C.K. Toge, S.A. John-Jaja, Journal of Agriculture and Ecology Research International (In Press). http://sciencedomain.org/journal/37/articles-press

[13] S.E. Etuk, S.C. Nwokolo, E.A. Okechukwu, S.A. John-Jaja, Journal of Geography, Environment and Earth Science International 7 (2016a) 1-15

[14] S.E. Etuk, S.C. Nwokolo, E.A. Okechukwu, Physical Science International Journal 12 (2016b) 1-12

[15] H.H. Kimball, Monthly Weather Research 47 (1919) 769-793 https://doi.org/10.1175/1520-0493(1919)47<769:VITTAL>2.0.CO;2.

[16] A. Angstrom, Quarterly Journal of Royal Meteorological Society 50 (1924) 121-5. https://doi.org/10.1002/qj.49705021008.

[17] J.A. Prescott, Transactions of the Royal Society of Australia 48 (1940) 114-8.

[18] I.K. Page, In Preceedings of UN Conference on new Source of Energy (1960) $378-390$

[19] M.R. Rietveld, Agriculture and Meteorology 19(1978) 243-252 https://doi.org/10.1016/0002-1571(78)90014-6.

[20] O.S. Ohunakin, M.S. Adaramola, O.M. Oyewolu, R.O. Fagbenle, Front Energy (2013) 1-9.

[21] M.S. Adaramola, Renewable Energy 47 (2012) 38-44. https://doi.org/10.1016/j.renene.2012.04.005.

[22] E.E. Ituen, N.U. Esen, S.C. Nwokolo, E.G. Udo, Advances in

[23] D. Yakubu, D.W. Medugu, Ozean Journal of Applied Sciences 5 (2012) 221-228.

[24] B. Musa, U. Zangina, M. Aminu, APRN Journal of Engineering and Applied Sciences 7 (2012) 1623-1627.

[25] B.C. Isikwue, A.N. Amah, P.G. Agada, Global Journal of Science Frontier Research Physics and Space Science 12 (2012) 58-61.

[26] O.T. Kolebaje, L.O. Mustapha, Afr. Rev. Phys. 7 (2012) 145-163.

[27] A. Solomon, Journal of Energy in Southern Africa 24 (2013) 46-49.

[28] N.N. Gana, D.O. Akpootu, Advances in Applied Science Research 4 (2013a) 409-421.

[29] N.N. Gana, D.O. Akpootu, the International Journal of Engineering and Sciences 2 (2013b) 58-78.

[30] B. Isikwue, S. Dandy, M. Audu, Journal of Natural Sciences Research 3 (2013) 165-170.

[31] G.N. Okonkwo, A.O.C. Nwokoye, European Scientific Journal 10 (2014a.) 1857-7431.

[32] E.O. Ogolo Indian Journal of Radio \& Space Physics 43 (2014) 213 224.

[33] A.O.C. Nwokoye, G.N. Okonkwo, IOSR J. Appl. Phys. 6 (2014)1516.

[34] M.S. Kaltiya, M.S. Abubakar, I.N. Itodo, American Journal of Engineering Research 3 (2014) 145-150.

[35] M.A. Sheriff, A.A. Goje, M.W. Zannah, Nigerian Journal of Physics 25 (2014) 35-39.

[36] C.U. Ike, APRN Journal of Sciences and Technology 4 (2014) 678683.

[37] N.N. Gana, K.R. Jitendru, M. Momoh, International Journal of Scientific and Engineering Research 5 (2014) 1636-1647.

[38] T.R. Ayodele,A.S.O. Ogunnjuyigb, Energy 90 (2015) 1732-1742 https://doi.org/10.1016/j.energy.2015.06.137.

[39] G.D. Sani, E.T. Mohd, B.G. Mohd, M.G. Usman, G.A., Musa, Advances in Physics Theories and Application 35 (2015) 55-61

[40] M.A. Adesina, J.S. Ibrahim, U.D. Ponzi, International Journal of Modern Engineering Sciences 4 (2015) 22-30.

[41] G.I. Olatona, A.E. Adeleke, The International Journal of Engineering and Science 4 (2015) 44-51.

[42] A.J. Innocent, O.E. Jacob, G.C. Chibuzo, I. James, D.O. Odeh, International Journal of Research in Engineering and Technology 3 (2015) 27-32.

[43] J.T. Azoom, J.U. Ugwuanyi, E.L. Echi, International Journal of Engineering and Computer Science. 4 (2015) 14677-14685

[44] U.E. Akpan, A.D. Osu, International Journal of Innovation in Science and Mathematics. 3 (2015) 112-117

[45] F.O. Ogunsanwo, J.O. Adepitan, V.C. Ozebo, J.D. Ayanda, International Journal of Physical Sciences. 11 (2016) 32-39 https://doi.org/10.5897/IJPS2015.4422.

[46] M.O. Boluwaji, D.O. Onyedi, Journal of Solar Energy 10 (2016) 1 7. 
[47] M.S. Okundamiya, J.O. Emagbethre, E.A. Ogujor, International Journal of Green Energy 13 (2016) 505-512. https://doi.org/10.1080/15435075.2014.968921.

[48] T.R. Ayodele, A.S.O. Ogunjuyigbe, International Journal of Ambient Energy Doi: 10.1080/01430750.2016. 2016

[49] A. Mohammad, T.H. Darwa, IOSR Journal of Applied Physics 6 (2014) 19-23. https://doi.org/10.9790/4861-06611923.

[50] O.T. Kolebaje, A.I. Sika, P. Akinyemi, International Journal of Energy Production and Management 1 (2016) 253-262. https://doi.org/10.2495/EQ-V1-N3-253-262.

[51] G.H. Hargreaves, R.G. Allen, Journal of irrigation and Drainage Engineering 129 (2003) 53-63 https://doi.org/10.1061/(ASCE)07339437(2003)129:1(53)

[52] G.H. Hargreaves, Z.A. Samani, J. Irrig. Drain. Eng. 108 (1982) 223230.

[53] J.V. Garcia, Principios F'isicos de la Climatolog'ia, Ediciones (UNALM Universidad Nacional Agracia La Molina, Lima, Peru 1994

[54] P.E. Ugwuoke, C.E. Okeke, International Journal of Renewable Energy Research 2 (2012) 269-273.

[55] A.O. Adekunle, C.O. Emmanuel, International Journal for Innovation Education and Research 2 (2014) 41-56

[56] E.O. Falayi, Energy and Power. 3 (2013) 119-127

[57] O.O. Ajayi, O.D. Ohijeagbon, C.E. Nwadialo, O. Olasope, Sustainable Energy Technologies and Assessments 5 (2014) 28-36. https://doi.org/10.1016/j.seta.2013.11.001.

[58] G.F. Ibeh, G.A. Agbo, Advances in Applied Science Research. 3 (2012) 12-18

[59] G.F. Ibeh, G.A. Agbo, P.A. Ukpai, D.O. Ugbor, Prime Journal of Physical Sciences. 1(2012a) 5-8

[60] G.F. Ibeh,G.A. Agbo, S. Rabia, A.R. Chukwuenzie, International Journal of Physical Sciences. 7 (2012b) 1162-1168

[61] G.F. Ibeh, G.A. Agbo, P.E., Ona, Archives of Applied Science Research. 4 (2012c)1213-1219

[62] G.A. Agbo, G.F. Ibeh, J.E. Ekpe, Research Journal of Recent Sciences. 1 (2012) 27-31

[63] S.C. Chukwu, A.N. Nwachukwu, Africa Journal of Environmental Science and Technology $6 \quad$ (2013) $182 \quad-188$ https://doi.org/10.5897/AJEST11.350.

[64] O.A. Bamiro, Solar Energy $31 \quad$ (1983) $85 \quad-\quad 94$ https://doi.org/10.1016/0038-092X(83)90038-5.

[65] R.K. Swartman, O. Ogunlade, Solar Energy. 11 (1967) 170-172 https://doi.org/10.1016/0038-092X(67)90026-6.

[66] F.W. Burari, A.S. Sambo, Journal of Tropical Engineering 4 (2003) $26-31$

[67] C. Augustine, M.N. Nnabuchi, Africa Journal of Environmental Science and Technology 4 2010) 92-99.

[68] Y.K. Sanusi, S.G. Abisoye, A.O. Abiodun, International Journal of Current Engineering and Technology. 3 (2013) 647-652

[69] D.I. Egeonu, H.O. Njoku, P.N. Okolo, S.O. Enibe, Advance Intelli$\begin{array}{lllll}\text { gent Systems and Computing. } 334 & \text { (2015) 109-12 }\end{array}$ https://doi.org/10.1007/978-3-319-13572-4_9.

[70] 1. Olatomiwa, S. Mekhilef, S. Shamshirbard, U. Petkovic. Renewable $\begin{array}{lllll}\text { and } & \text { Energy } & \text { Reviews. } & 51 & \text { (2015) }\end{array}$ https://doi.org/10.1016/j.rser.2015.05.068.

[71] J.K. Yohanna, I.S. Itodo, V.I. Umogba, Pac. J. Sci. Technol. 10 (2009) 574-579.

[72] Y.A. Abdalla, International Journal of Solar Energy. 16 (1994) 111120 https://doi.org/10.1080/01425919408914270.

[73] V. Bahel, A. Bakhsh, R. Srinivasan, Energy 12 (1987) 131-135 https://doi.org/10.1016/0360-5442(87)90117-4.

[74] K. Bakiri,Energy 34 (2009) 485-501. https://doi.org/10.1016/j.energy.2009.02.005

[75] Z. Ramedani, M. Omid, A. Keyhani, S. Shanshirband, B. Khoshnervisan,Renewable and Sustainable Energy Reviews. 39 (2014) 1005-10 https://doi.org/10.1016/j.rser.2014.07.108.

[76] H. Glover, G.J. McCulloh, F. McCulloh, Quarterly Journal of Royal $\begin{array}{llll}\text { Meteorological } & \text { Society. } & 84 & \text { (1958) }\end{array}$ https://doi.org/10.1002/qj.49708435907.

[77] R.G. Allen, L.S. Pereira D. Raes, M. Smith, FAO Irrigation and Drainage Paper, Rome, Italy. 56 (1998) p. 290. 